\title{
Highly Ordered Graphene Solid: An Efficient Platform for \\ Capacitive Sodium-Ion Storage with Ultrahigh Volumetric Capacity and Superior Rate Capability
}

Hongyun Ma ${ }^{\dagger}$ Hongya Geng, ${ }^{\dagger}$ Bowen Yao,${ }^{\dagger}$ Mingmao $W u,{ }^{\dagger}$ Chun Li $,{ }^{*},{ }^{\dagger}$ Miao Zhang, ${ }^{\dagger}$ Fengyao Chi, ${ }^{\dagger}$ and Liangti $Q u^{*, \dagger, \downarrow, \S}$

†MOE Key Laboratory of Bioorganic Phosphorus Chemistry \& Chemical Biology, Department of Chemistry, Tsinghua University, Beijing 100084, P. R. China.

†ey Laboratory for Advanced Materials Processing Technology, Ministry of Education of China; State Key Laboratory of Tribology, Department of Mechanical Engineering, Tsinghua University, Beijing 100084, P. R. China.

${ }^{\S}$ School of Chemistry and Chemical Engineering, Beijing Institute of Technology, Beijing 100081, P. R. China.

*Corresponding author: chunli@mail.tsinghua.edu.cn; lqu@ mail.tsinghua.edu.cn 
Preparation of graphene oxide. Graphene oxide (GO) was prepared via the modified Hummers method. Typically, graphite powder (8 g, 325 mesh) and sodium nitrate (4 g) was slowly added to concentrated sulphuric acid $(200 \mathrm{~mL}, 98 \%)$ under constant agitation at room temperature. The reaction system was then transferred to an ice-water bath and vigorously agitated for $30 \mathrm{~min}$, after which potassium permanganate (32 g) was slowly added and maintained the temperature of the suspension below $5{ }^{\circ} \mathrm{C}$. After agitated for $2 \mathrm{~h}$, the reaction mixture was transferred to a $35^{\circ} \mathrm{C}$ water bath and agitated for another $30 \mathrm{~min}$. Subsequently, $300 \mathrm{~mL}$ of deionized water was slowly added by a constant flow pump, and the mixture was then agitated for another $40 \mathrm{~min}$ at $98^{\circ} \mathrm{C}$. An additional $500 \mathrm{~mL}$ of deionized water was added and then hydrogen peroxide $(40 \mathrm{~mL}$, $30 \%)$ was added to terminate the reaction. The mixture was filtered and washed with hydrochloric acid $(100 \mathrm{~mL}, 5 \%)$ to remove metal ions followed by washing with deionized water to remove the residual acid. The resultant slurry was dispersed in 1200 $\mathrm{mL}$ of deionized water under vigorous stirring to form a $\mathrm{GO}$ aqueous dispersion. The resultant GO dispersion was subjected to dialysis (cut off of 8000 14000 Da) for 15 days to remove the residual acid and metal impurities. Finally, the GO suspension was purified repeatedly by centrifugation at $2000 \mathrm{rpm}$ for $20 \mathrm{~min}$ to remove unexfoliated graphite oxide particles, followed by concentration at $10000 \mathrm{rpm}$ for $60 \mathrm{~min}$.

Capillary densification of HOGH. Capillary densification, also called evaporationinduced capillary densification, is a simple soft approach to densify graphene hydrogels and gel-films via the capillary pressure induced by solvent evaporation. It can be easily carried out by simply drying the graphene hydrogels or gel-films in a vacuum oven or directly in the ambient air. In our case, the highly ordered graphene hydrogel (HOGH) was dried in a vacuum oven at $55{ }^{\circ} \mathrm{C}$ for $24 \mathrm{~h}$, and then compact yet highly ordered graphene solid (HOGS) was successfully prepared.

Electrochemical calculation. Unless specifically mentioned, all the electrochemical performances are calculated based on active materials (i.e., HOGS or CGS), and the 
related formulas are shown below.

The gravimetric capacitance was calculated from the GCD curves using the formula:

$$
C_{\mathrm{g}}=I \times \Delta t /(m \times \Delta U)
$$

where $C_{\mathrm{g}}\left(\mathrm{F} \mathrm{g}^{-1}\right)$ is the gravimetric capacitance, $I(\mathrm{~A})$ is the discharge current, $\Delta t(\mathrm{~s})$ is the discharge time, $m(\mathrm{~g})$ is the mass of active material, and $\Delta U(\mathrm{~V})$ is the potential window during the discharge process (excluding the IR drop).

The volumetric capacitance was calculated as:

$$
C_{\mathrm{v}}=\rho \times C_{\mathrm{g}}
$$

where $C_{\mathrm{v}}\left(\mathrm{F} \mathrm{cm}^{-3}\right)$ is the volumetric capacitance, $\rho\left(\mathrm{g} \mathrm{cm}^{-3}\right)$ is the packing density of the active material.

The volumetric energy/power densities of HOGS based SIC were also calculated by assuming that the anode material coupled with HOGS possesses an identical specific capacity and a loading mass with HOGS, as well as the same operating voltage with sodium foil. The volumetric energy density of HOGS based SIC was calculated as:

$$
E_{\mathrm{vol}}=0.25 \times C_{\mathrm{v}} \times \Delta U^{2} / 3.6
$$

where $E_{\mathrm{vol}}\left(\mathrm{Wh} \mathrm{L}^{-1}\right)$ is the volumetric energy density of HOGS based SIC, $C_{\mathrm{v}}\left(\mathrm{F} \mathrm{cm}^{-3}\right)$ is the volumetric capacitance of active material and $\Delta U(\mathrm{~V})$ is the potential window.

The volumetric power density of HOGS based SIC was calculated as:

$$
P_{\mathrm{vol}}=3600 \times E_{\mathrm{vol}} / \Delta t
$$

where $P_{\mathrm{vol}}\left(\mathrm{W} \mathrm{L}^{-1}\right)$ is the volumetric power density of HOGS based SIC, $E_{\mathrm{vol}}\left(\mathrm{Wh} \mathrm{L}^{-1}\right)$ is its volumetric energy density and $\Delta t(\mathrm{~s})$ is the discharge time.

Additionally, the electrochemical performances based on whole electrode (containing active material, conductive additive, and binder) are calculated as below. The gravimetric capacitance of the electrode was calculated by using the formula:

$$
C_{\mathrm{g}}{ }^{\prime}=I \times \Delta t /\left(m^{\prime} \times \Delta U\right)
$$

where $C_{\mathrm{g}^{\prime}}\left(\mathrm{F} \mathrm{g}^{-1}\right)$ is the gravimetric capacitance of the electrode, $I(\mathrm{~A})$ is the discharge current, $\Delta t(\mathrm{~s})$ is the discharge time, $m^{\prime}(\mathrm{g})$ is the mass of the electrode, and $\Delta U(\mathrm{~V})$ is the potential window during the discharge process (excluding the IR drop). 
The volumetric capacitance of the electrode was calculated as:

$$
C_{\mathrm{V}}{ }^{\prime}=\rho^{\prime} \times C_{\mathrm{g}}{ }^{\prime}
$$

where $C_{\mathrm{v}}{ }^{\prime}\left(\mathrm{F} \mathrm{cm}^{-3}\right)$ is the volumetric capacitance of the electrode, $\rho^{\prime}\left(\mathrm{g} \mathrm{cm}^{-3}\right)$ is the density of the HOGS based electrode.

The density of the HOGS based electrode by using the following formula:

$$
\rho^{\prime}=m^{\prime} / V^{\prime}=m^{\prime} /\left(S^{\prime} \times h^{\prime}\right)
$$

Where $\rho^{\prime}\left(\mathrm{g} \mathrm{cm}^{-3}\right)$ is the density of the HOGS based electrode, $m^{\prime}(\mathrm{g}), V^{\prime}\left(\mathrm{cm}^{3}\right), S^{\prime}\left(\mathrm{cm}^{2}\right)$, and $h^{\prime}(\mathrm{cm})$ are the mass, volume, area, and thickness of the HOGS based electrode (including active material, conductive additive and binder), respectively. 

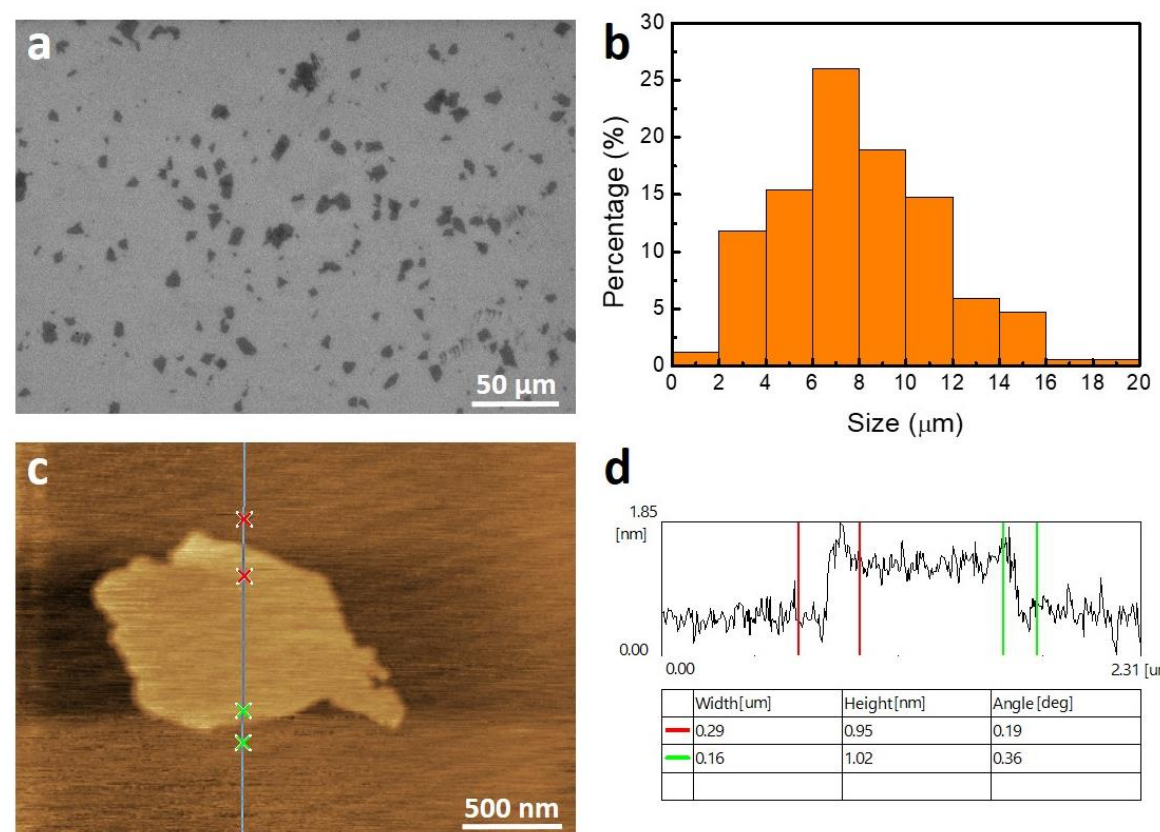

\section{d}

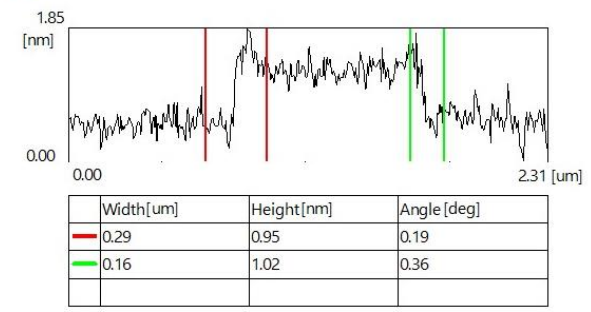

Figure S1. SEM image a) and corresponding size distribution b) of GO sheets. AFM image c) and corresponding height profile d) of a GO sheet.
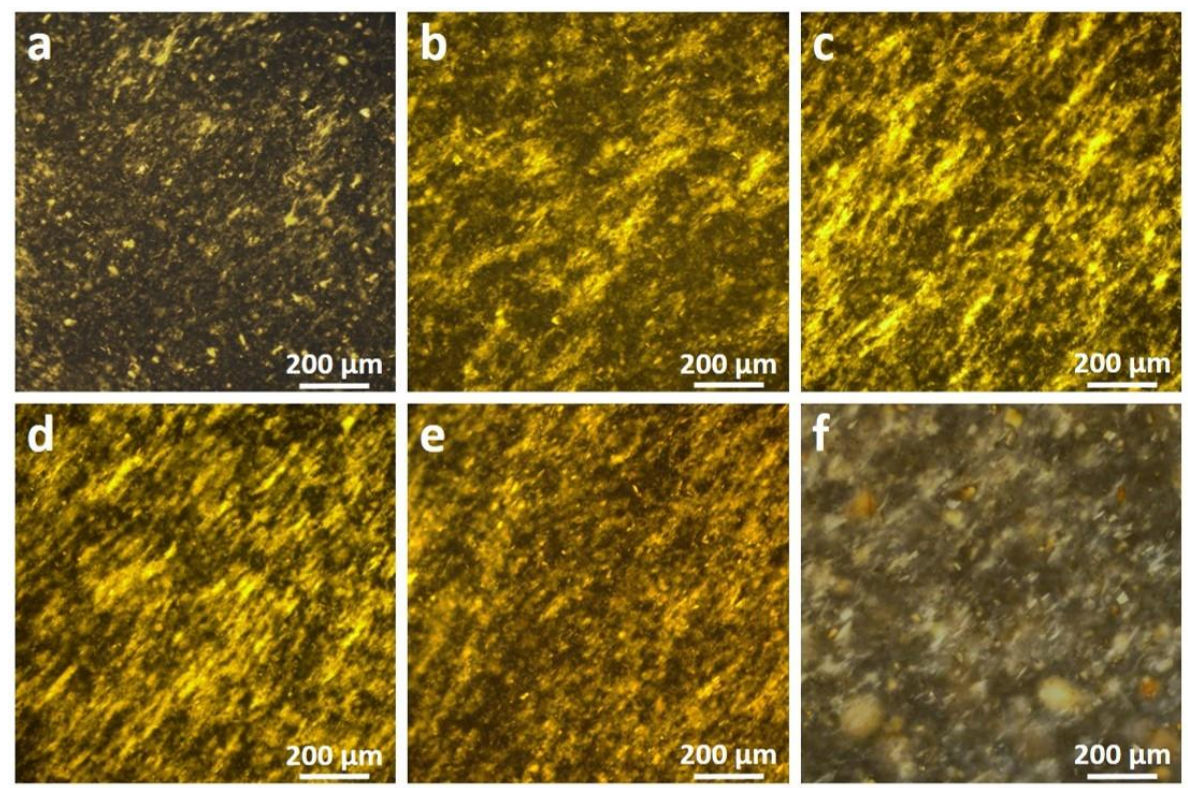

Figure S2. POM images of GO suspensions $\left(3 \mathrm{mg} \mathrm{mL}^{-1}\right)$ containing diffrent amount of $\mathrm{KOH}$ : a) 0, b) 0.05 , c) 0.10 , d) 0.12 , e) 0.15 , and f) $0.20 \mathrm{~mol} \mathrm{~L}^{-1}$. $\mathrm{KOH}$ can promote the formation of long-rang oriented lamellar GO LCs upon increasing the concentration of $\mathrm{KOH}$ from 0 to $0.12 \mathrm{~mol} \mathrm{~L}^{-1}$. However, a larger amount of $\mathrm{KOH}\left(>0.15 \mathrm{~mol} \mathrm{~L}^{-1}\right.$ ) will lead to the flocculation of GO sheets due to the salting-out effect, as revealed by Zeta potential and apparent viscosity tests (Figure S3). 

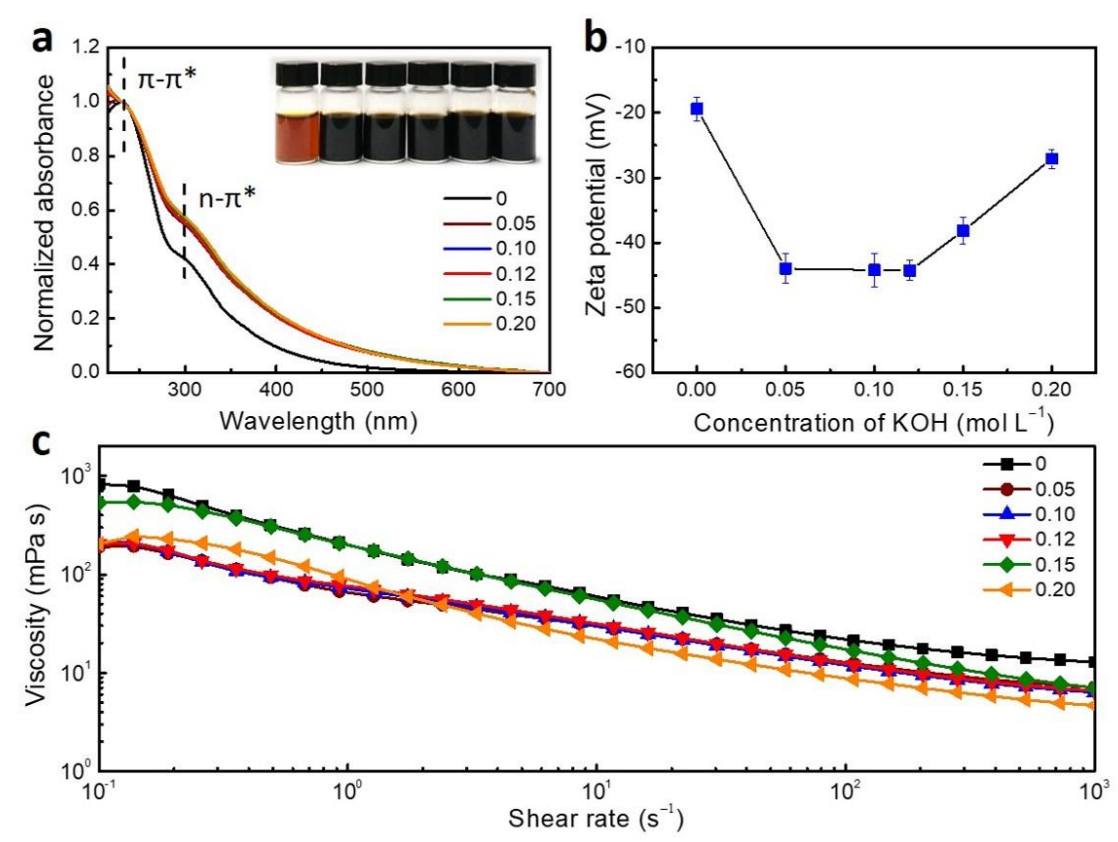

Figure S3. UV-vis spectra a), Zeta potentials b), and apparent viscosities c) of GO suspensions ( $3 \mathrm{mg} \mathrm{mL}^{-1}$ ) containing diffrent amount of $\mathrm{KOH}$ ranging from 0 to 0.20 mol L ${ }^{-1}$. Compared with pure GO suspension, the GO suspensions containing $\mathrm{KOH}$ show a stronger and broader $n-\pi^{*}$ absorbance on their UV-vis spectra, reflecting the partial recovery of the conjugated domains on GO sheets. The darkening of the suspensions after adding $\mathrm{KOH}$ also supports this point. Besides, the GO suspensions with appropriate amount of $\mathrm{KOH}\left(<0.12 \mathrm{~mol} \mathrm{~L}^{-1}\right)$ exhibit a lower Zeta potential than that of pure $\mathrm{GO}$ suspension, implying that $\mathrm{KOH}$ can promote the ionization of the oxygenated groups on GO sheets and thus enhance the electrostatic repulsion between $\mathrm{GO}$ sheets. However, a higher concentration of $\mathrm{KOH}\left(>0.15 \mathrm{~mol} \mathrm{~L}^{-1}\right)$ will weaken the electrostatic repulsion between GO sheets as revealed by the higher Zeta potentials. This is mainly attributed to the neutralization the electric double-layer of colloidal GO sheets by high-concentration potassium ions (i.e., salting-out effect). The viscosity tests show a similar phenomenon. Namely, the GO suspensions with appropriate amount of $\mathrm{KOH}\left(<0.12 \mathrm{~mol} \mathrm{~L}^{-1}\right)$ exhibit a lower viscosity owing to the enhanced electrostatic repulsion between GO sheets. However, a larger amount of $\mathrm{KOH}$ will reslut in the flocculation $\left(0.15 \mathrm{~mol} \mathrm{~L}^{-1}\right)$ or even the precipitation $\left(0.20 \mathrm{~mol} \mathrm{~L}^{-1}\right)$ of $\mathrm{GO}$ sheets. 

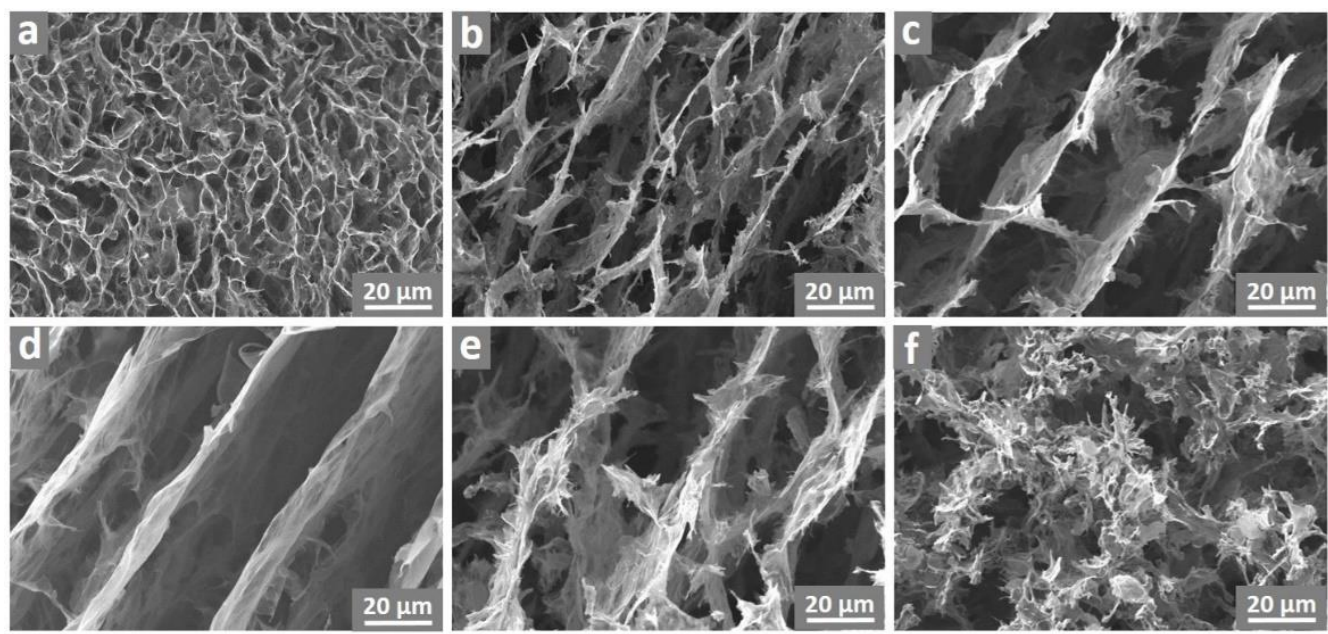

Figure S4. SEM images of the freezing-dried graphene hydrogels preparaed form dirrerent precusors, namely GO suspensions $\left(3 \mathrm{mg} \mathrm{mL}^{-1}\right)$ containing diffrent amount of $\mathrm{KOH}$ : a) 0, b) 0.05 , c) 0.10 , d) 0.12 , e) 0.15 , and f) $0.20 \mathrm{~mol} \mathrm{~L}^{-1}$. The textures of GO suspensions can be well preserved upon hydrothermal reduction. Accordingly, the graphene hydrogel prepared from the GO suspension with $0.12 \mathrm{~mol} \mathrm{~L}^{-1} \mathrm{KOH}$ has an optimal long-range ordered lamellar microstructure, which is inherited from highly oriented lamellar GO LCs.
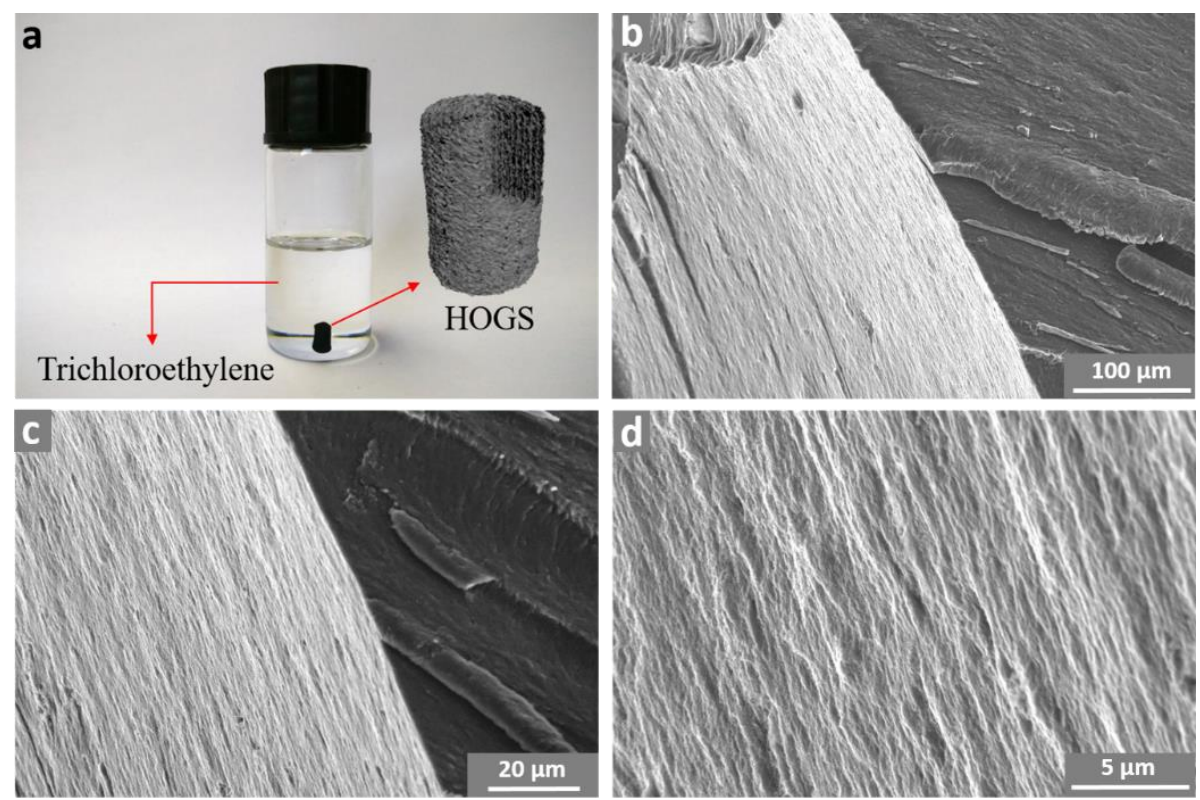

Figure S5. a) Optical image of HOGS in a high-density reference solvent (trichloroethylene, with a density of $1.46 \mathrm{~g} \mathrm{~cm}^{-3}$ ). b-d) SEM images of HOGS with different magnifications. 

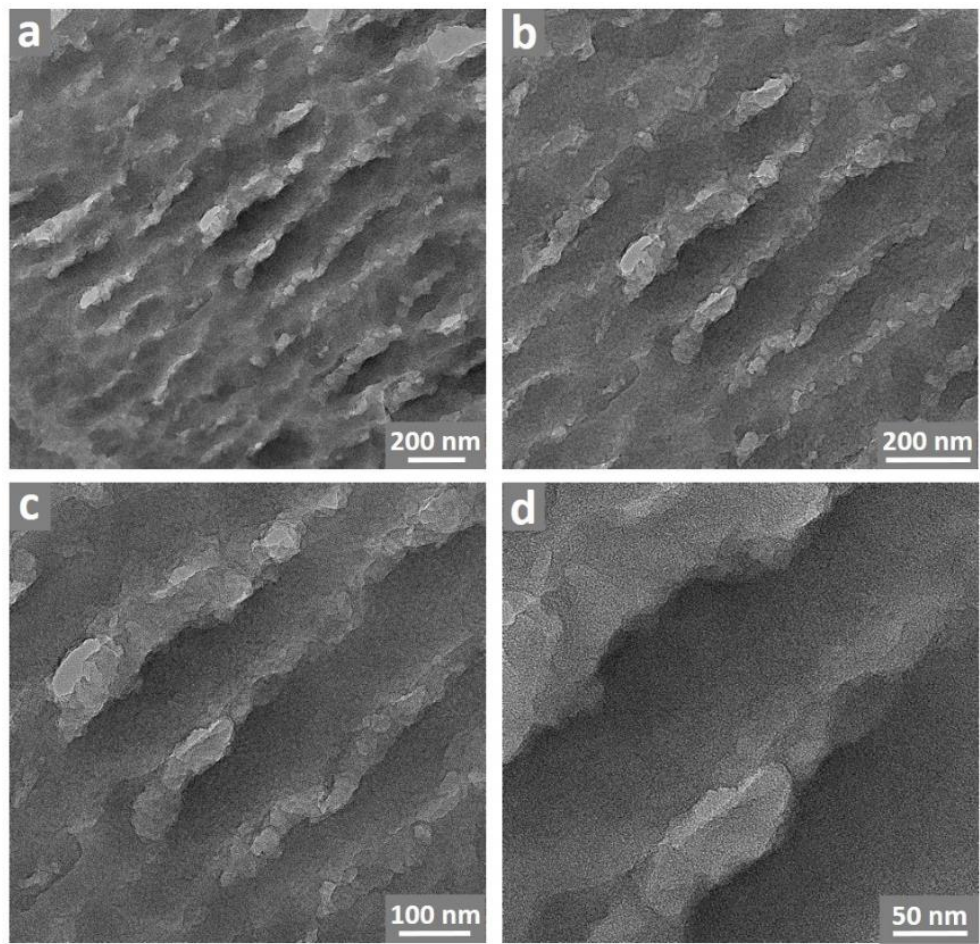

Figure S6. TEM images of the cross section of HOGS with different magnifications.
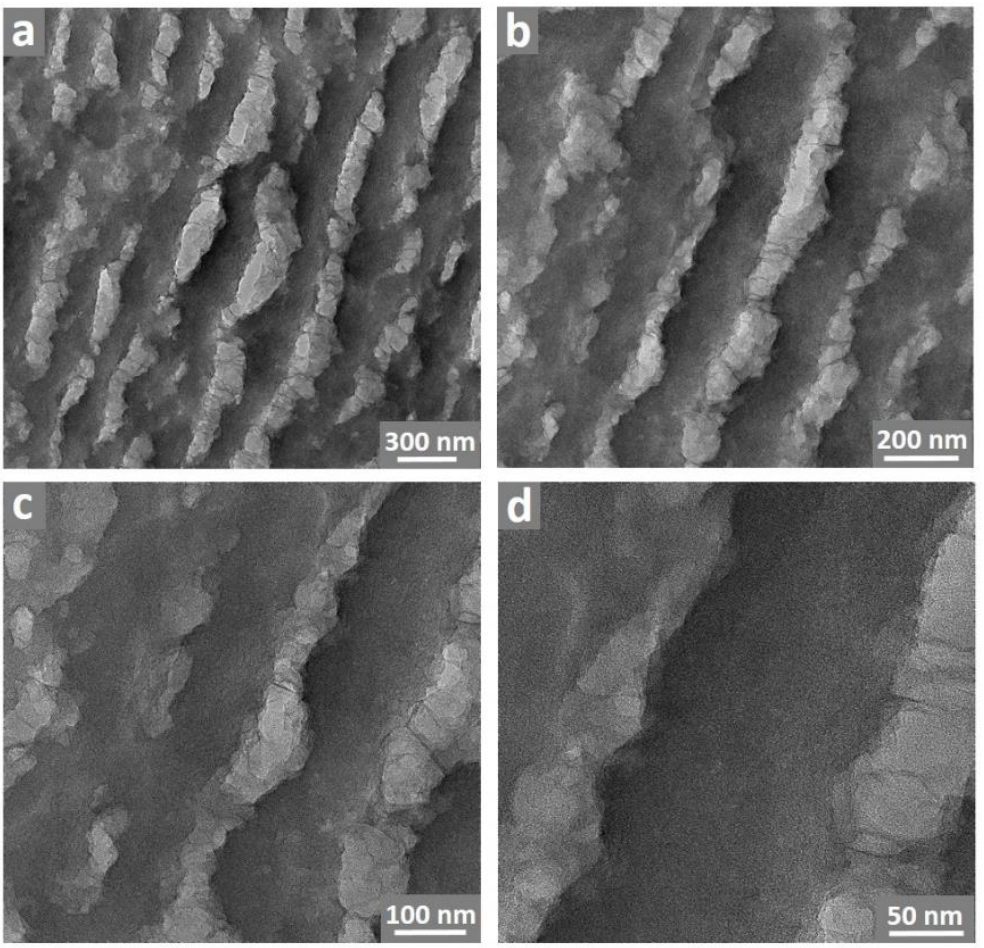

Figure S7. TEM images of the longitudinal section of HOGS with different magnifications. 

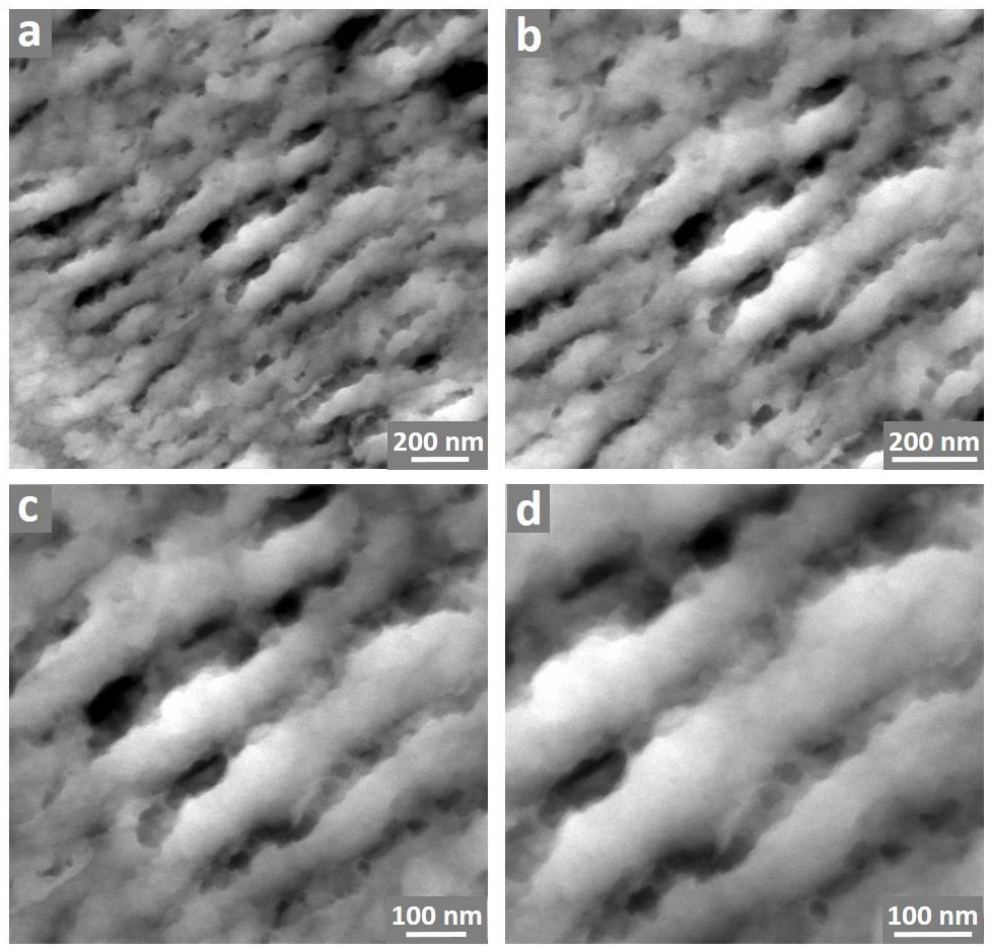

Figure S8. STEM images of the cross section of HOGS with different magnifications.
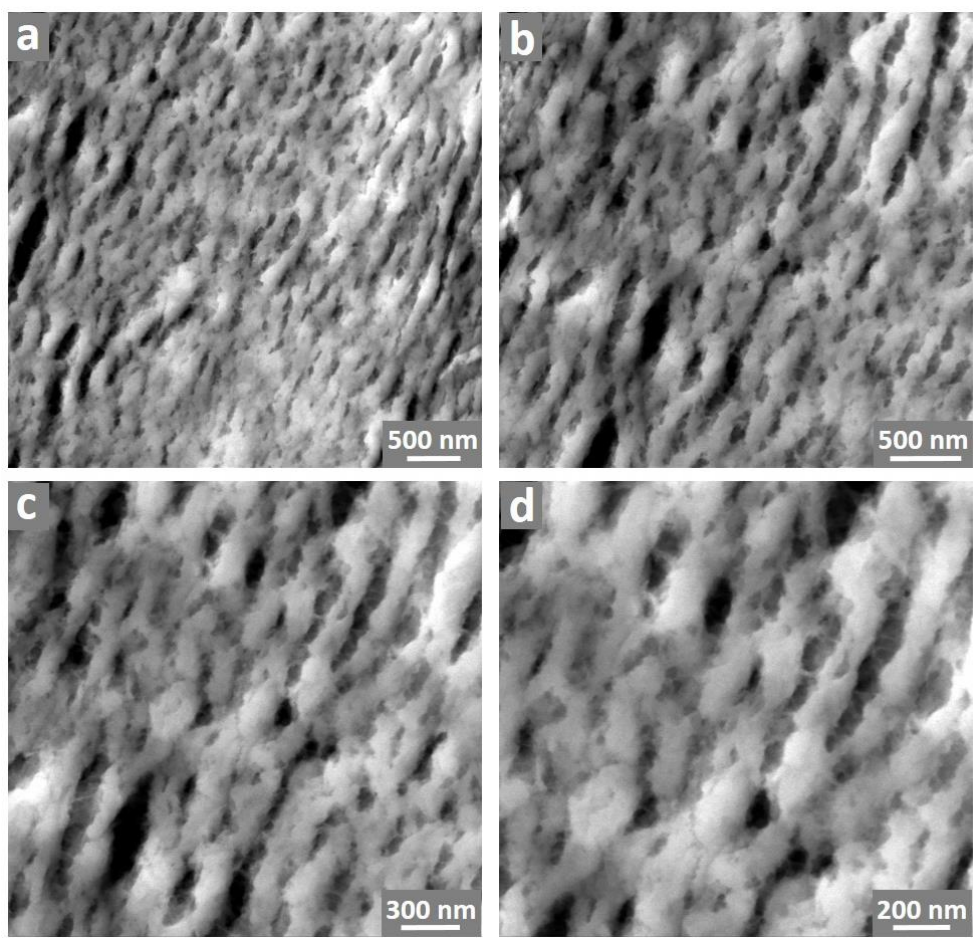

Figure S9. STEM images of the longitudinal section of HOGS with different magnifications. 

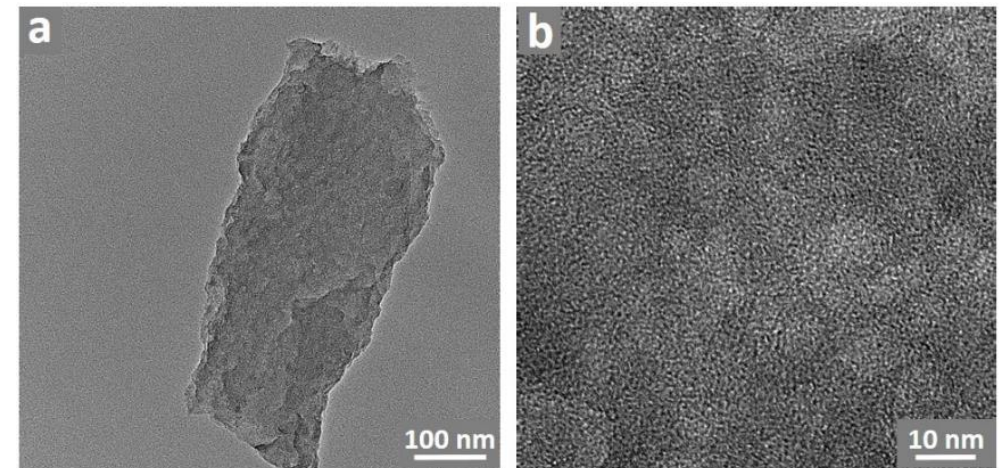

Figure S10. TEM images of graphene walls peeled from HOGS with different magnifications.
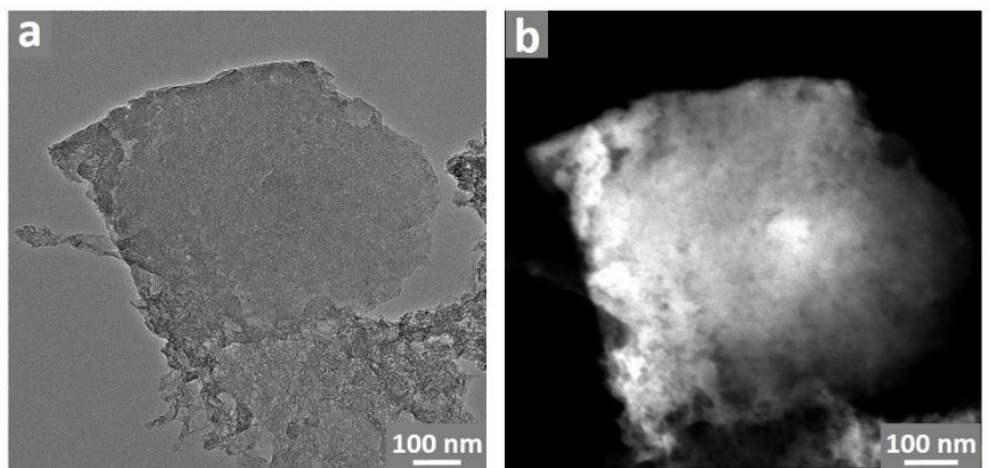

Figure S11. TEM a) and corresponding STEM b) images of graphene walls in the same place.

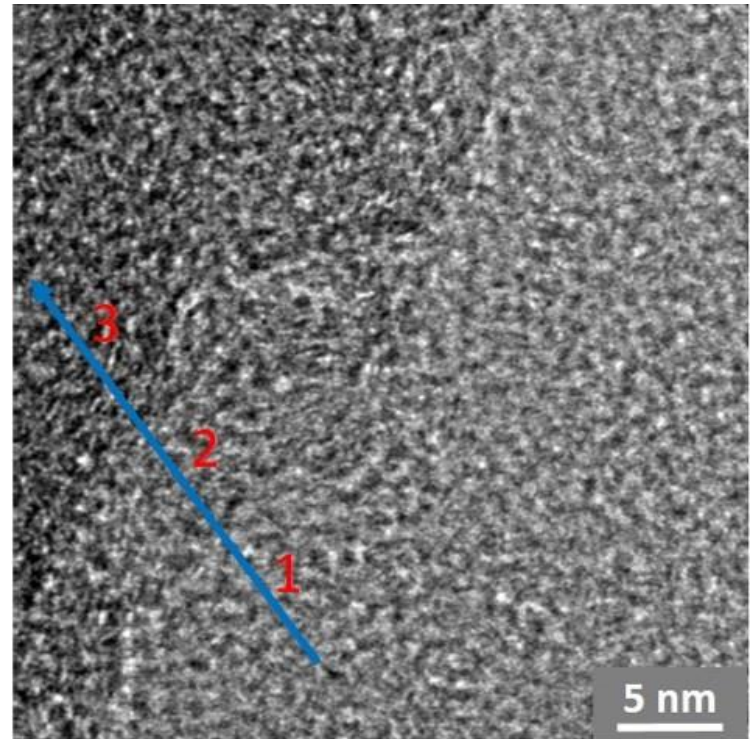

Figure S12. HRTEM image of the graphene wall peeled from HOGS. Similar to HOGH, the graphene walls in HOGS are multilayer in nature, and most of them are within three layers. 

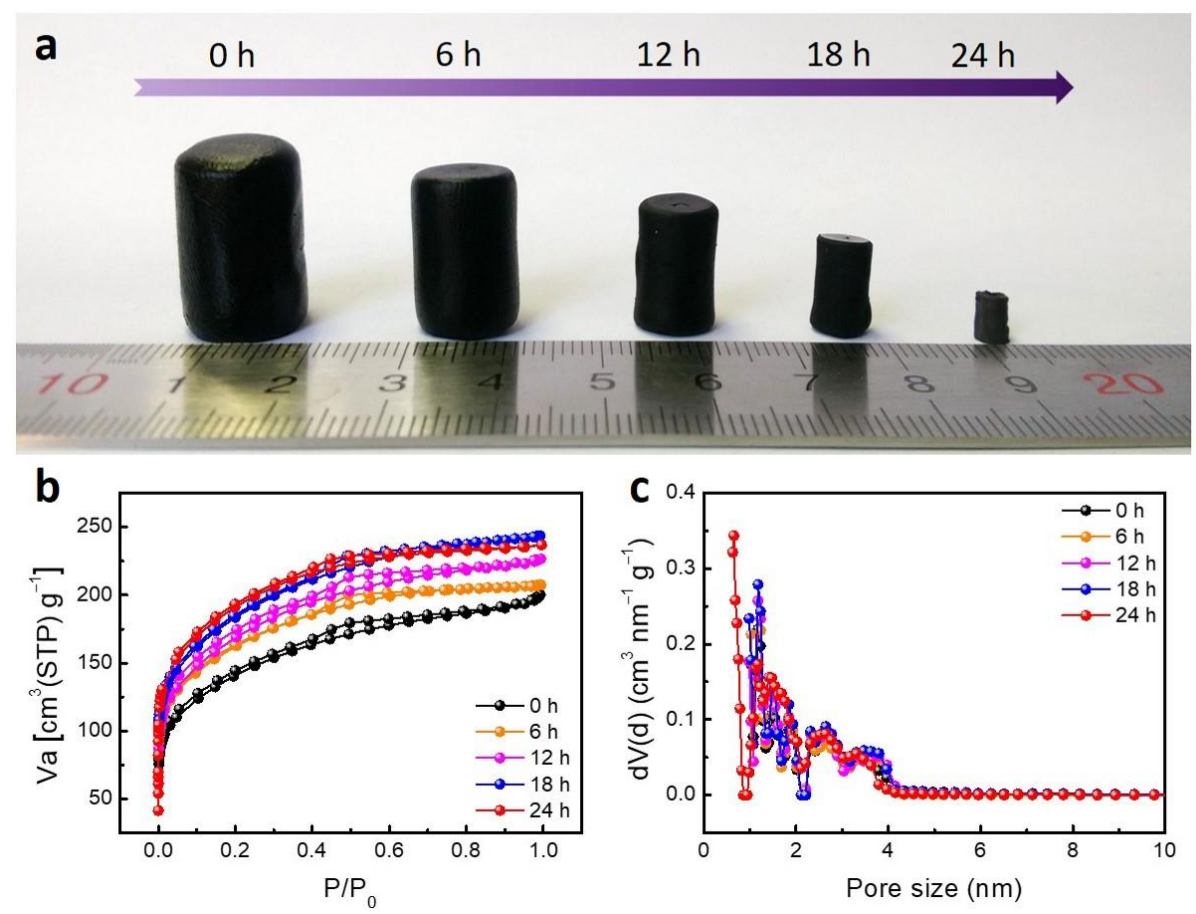

Figure S13. a) Optical image of capillary densified HOGHs with drying time ranging from 0 to 24 h. $\mathrm{N}_{2}$ adsorption/desorption isotherms b), and corresponding pore size distribution curves c) of freezing-dried HOGHs with differnet drying time. Owing to the lameller texture of $\mathrm{HOGH}$, the pores can be detected by $\mathrm{N}_{2}$ molecules are mainly micropors and mesopores. With the increase of the drying time, the volume of HOGH gradually shrinks, producing a lot of new micropores and mesopores. As a result, the completely densified sample (i.e., HOGS) possesses the highest packing density (1.48 $\mathrm{g} \mathrm{cm}^{-3}$ ) and the highest porosity (SSA, $529 \mathrm{~m}^{2} \mathrm{~g}^{-1}$ ). 

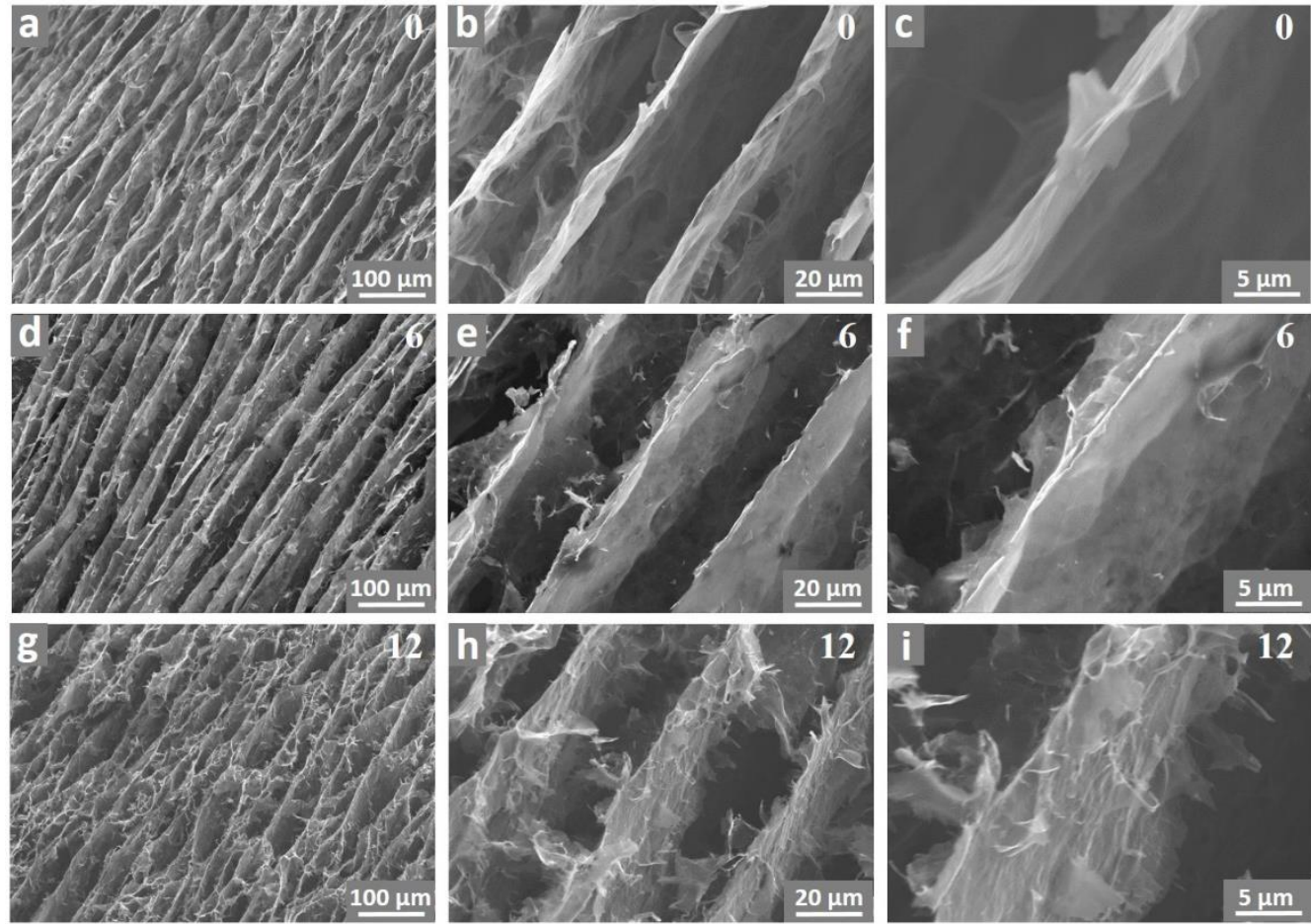

Figure S14. SEM images of freezing-dried HOGH after different time capillaryevaporation-induced densification: $0 \mathrm{~h} \mathrm{a}-\mathrm{c}), 6 \mathrm{~h} \mathrm{~d}-\mathrm{f}$ ), and $12 \mathrm{~h} \mathrm{~g}-\mathrm{i}$ ).
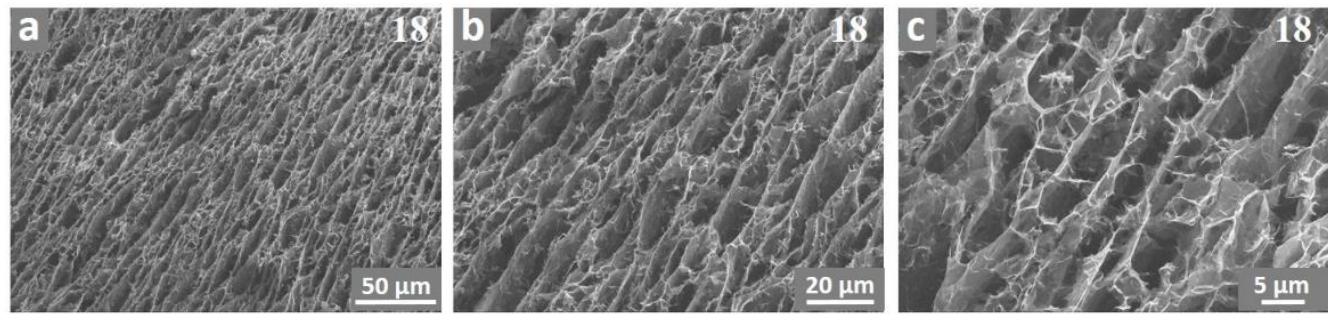

Figure S15. SEM images of freezing-dried HOGH after $18 \mathrm{~h}$ capillary-evaporationinduced densification. 

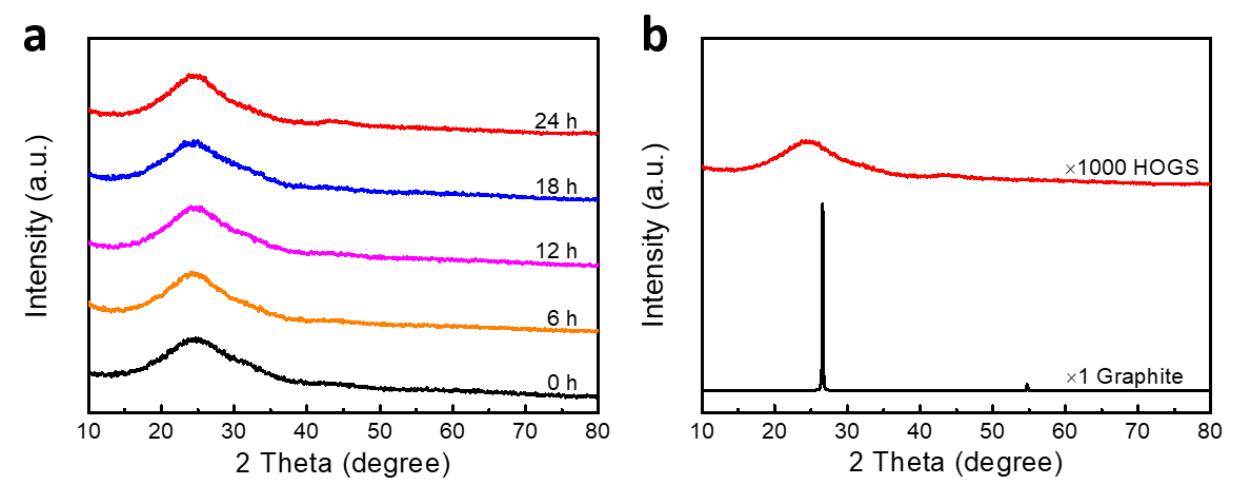

Figure S16. a) XRD patterns of capillary densified HOGHs with drying time ranging from 0 to 24 h. b) XRD patterns of HOGS and pristine graphite. The XRD patterns of capillary densified HOGHs with different drying times show almost identical (002) peaks with same peak positions and half-peak widths, implying that the layer number and interlayer distance of the graphene sheets in individual graphene walls are unchanged during the capillary densification process. Specifically, the interlayer distance of the graphene sheets was calculated to be $0.362 \mathrm{~nm}$ via Bragg Equation; this value is slightly larger than that of prinstine grapheite $(0.335 \mathrm{~nm})$.
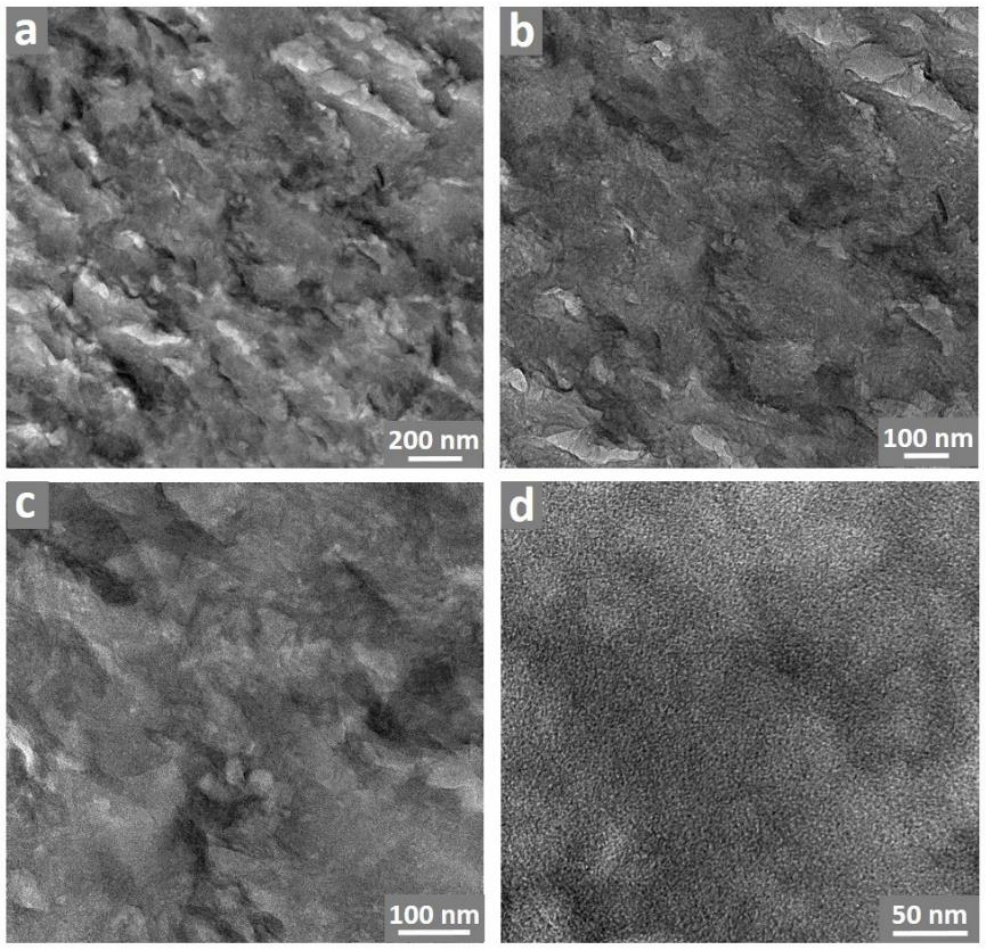

Figure S17. TEM images of the cross section of CGS with different magnifications. 

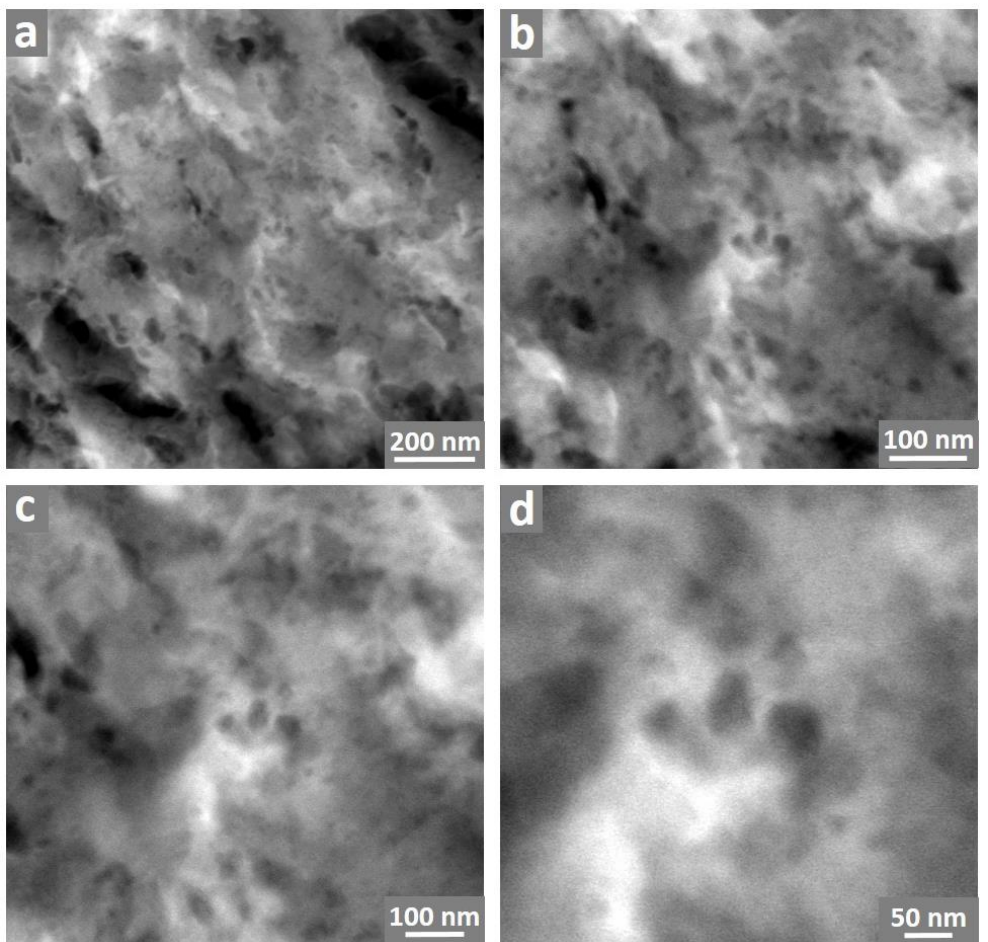

Figure S18. STEM images of the cross section of CGS with different magnifications.
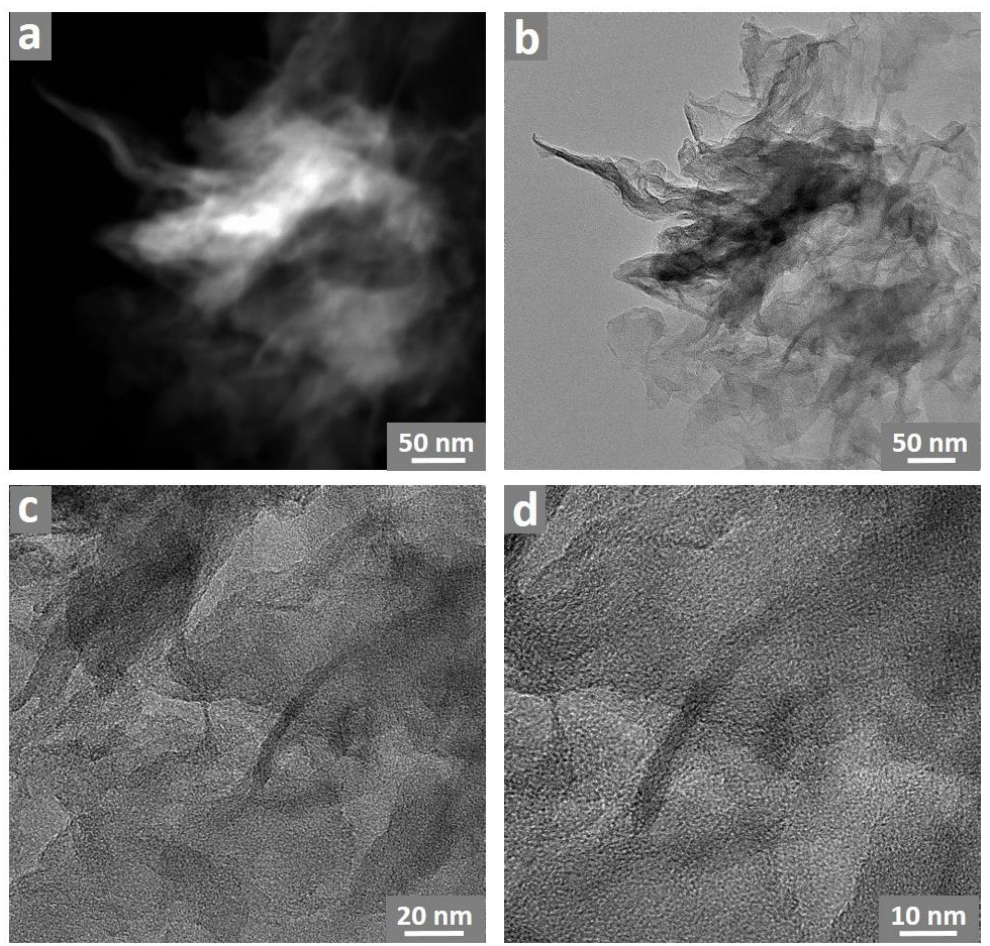

Figure S19. STEM a) and corresponding TEM b) images of the graphene piece peeled from CGS. c, d) TEM images with higher resolutions. 

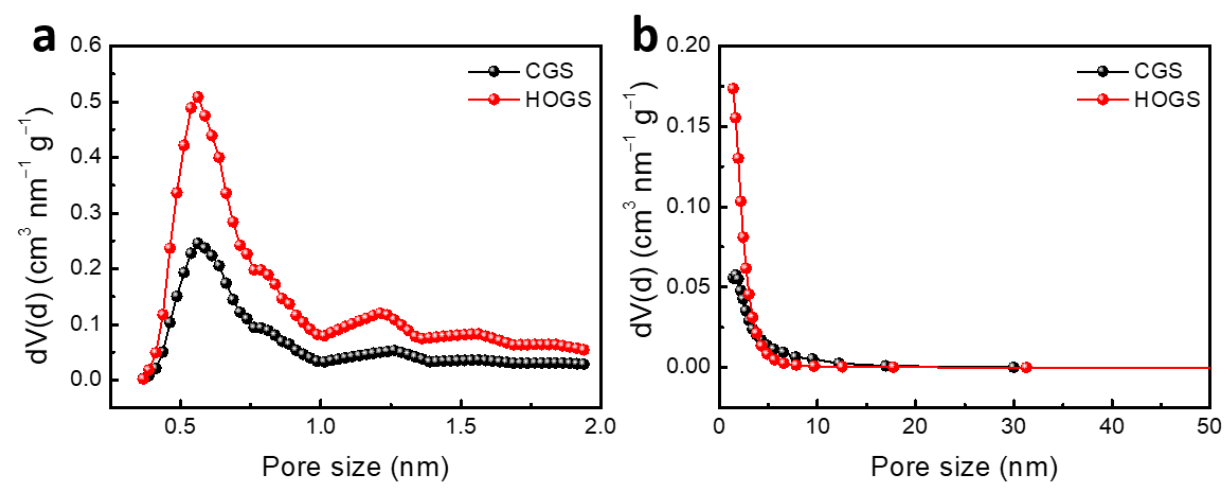

Figure S20. Pore size distribution curves of CGS and HOGS calculated by HK a) and $\mathrm{BJH}$ b) methods, respectively.

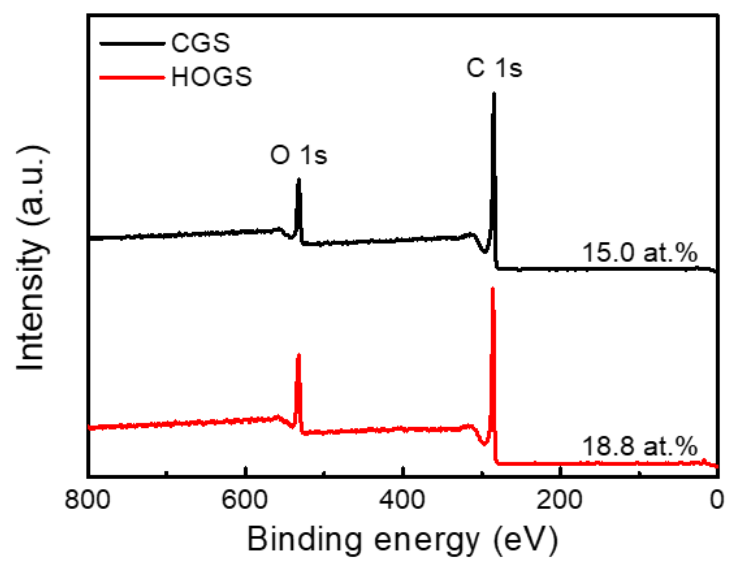

Figure S21. XPS surveys of CGS and HOGS. 

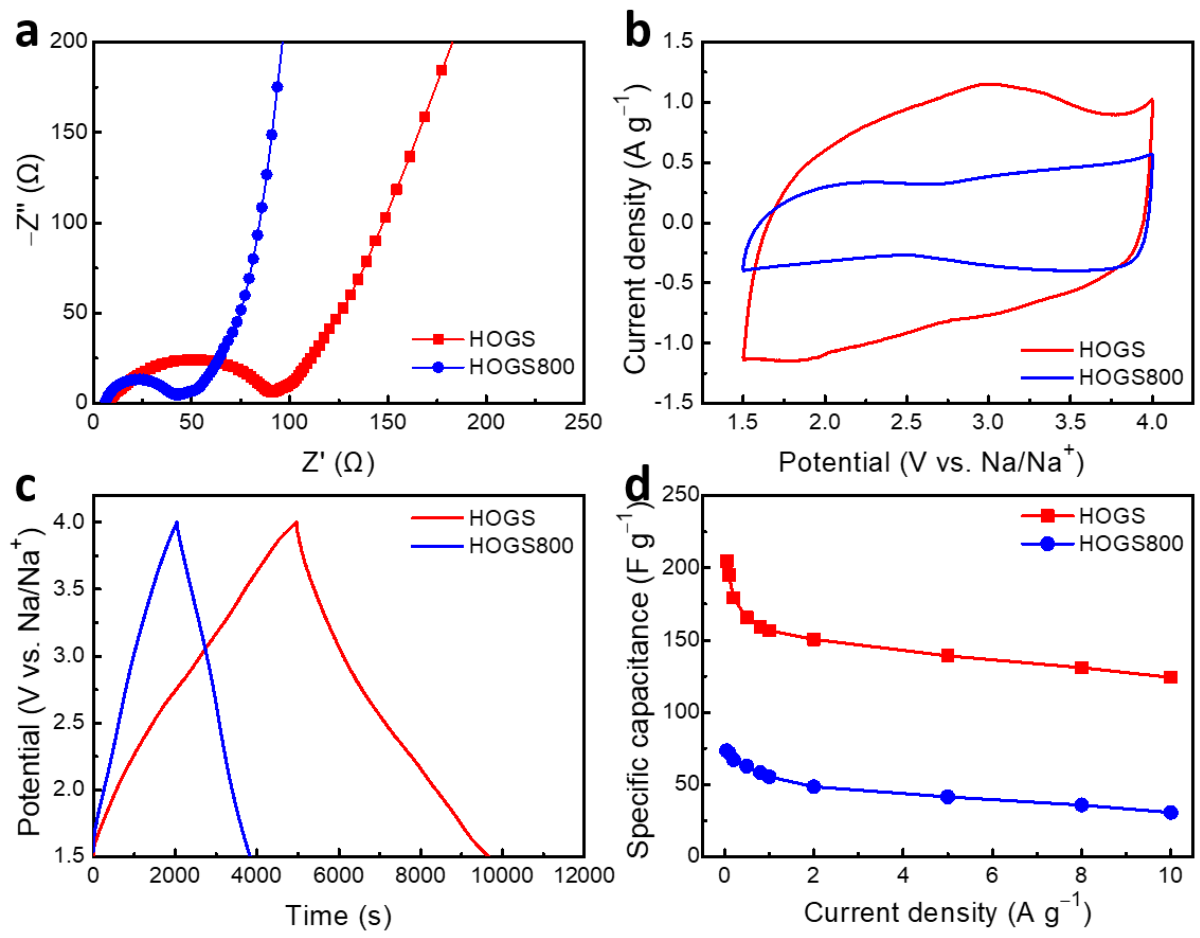

Figure S22. Electrochemical performance comparison of HOGS and HOGS800. a) Nyquist plots. b) CV curves at the scan rate of $5 \mathrm{mV} \mathrm{s}^{-1}$. c) GCD curves at the current density of $0.1 \mathrm{~A} \mathrm{~g} \mathrm{~g}^{-1}$. d) Specific capacitances at current densities ranging from 0.05 to $10 \mathrm{~A} \mathrm{~g}^{-1}$. Upon annealing, HOGS eliminates most of its oxygenated groups which contribute Faraday pseudo-capacitance. According to this principle, the contribution of Faraday pseudo-capacitive reaction can be roughly calculated to be $68 \%$.
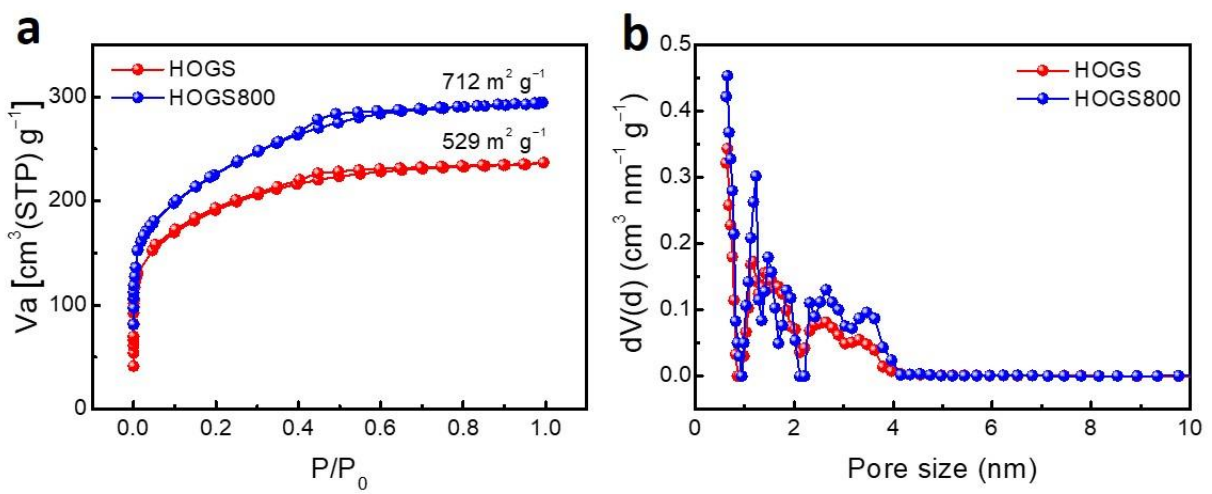

Figure S23. $\mathrm{N}_{2}$ adsorption/desorption isotherms a) and Pore size distribution curves b) of HOGS and HOGS800. 


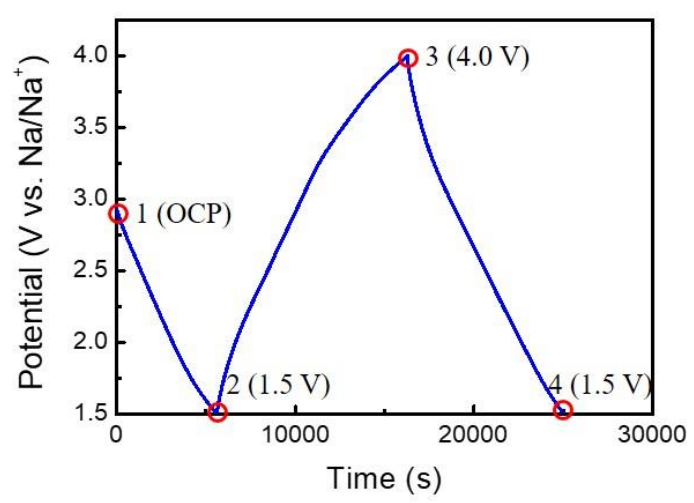

Figure S24. GCD curves of HOGS. In order to reveal the sodium-ion storage mechanism of HOGS, we carried out the ex situ XPS measurements at the different charge states: 1) open circuit potential (OCP), 2) discharged to $1.5 \mathrm{~V}, 3)$ charged to 4.0 $\mathrm{V}, 4)$ and redischarged to $1.5 \mathrm{~V}$.
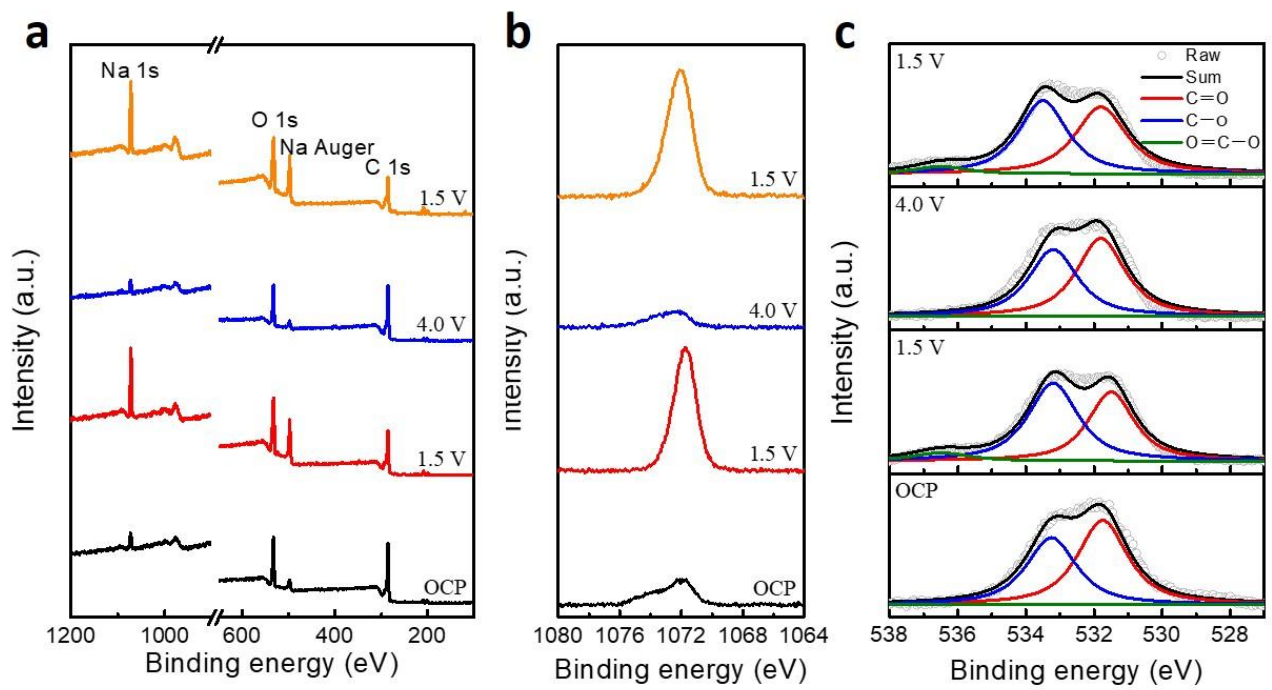

Figure S25. XPS surveys a), Na 1s core level spectra b), and O 1s core level spectra c) of HOGS at different charge states. When the HOGS was discharged to $1.5 \mathrm{~V}$ from OCP, the sodium atomic content was dramatically increased. This process is highly reversible when HOGS was charged to $4.0 \mathrm{~V}$ and redischarged to $1.5 \mathrm{~V}$, implying the sodium ions dominated energy storage mechanism. More details can be revealed from the variations of $\mathrm{O} 1 \mathrm{~s}$ core level spectra. As the HOGS was discharged to $1.5 \mathrm{~V}$, the intensity of $\mathrm{C}=\mathrm{O}$ groups was obviously decreased, with the intensity increases of $\mathrm{C}-\mathrm{O}$ groups. This result 
demonstrates that the active sites to store sodium ions are mainly $\mathrm{C}=\mathrm{O}$ groups, and the resulting products are $\mathrm{C}-\mathrm{O}-\mathrm{Na}$. Therefore, the sodium-ion storage mechanism can be expressed as: $>\mathrm{C}=\mathrm{O}+\mathrm{Na}^{+}+\mathrm{e}^{-} \leftrightarrow>\mathrm{C}-\mathrm{O}-\mathrm{Na}$. This Faraday reaction based pseudocapacitive sodium-ion storage mechanism reveraled by ex situ XPS studies is consistent with previous reports.

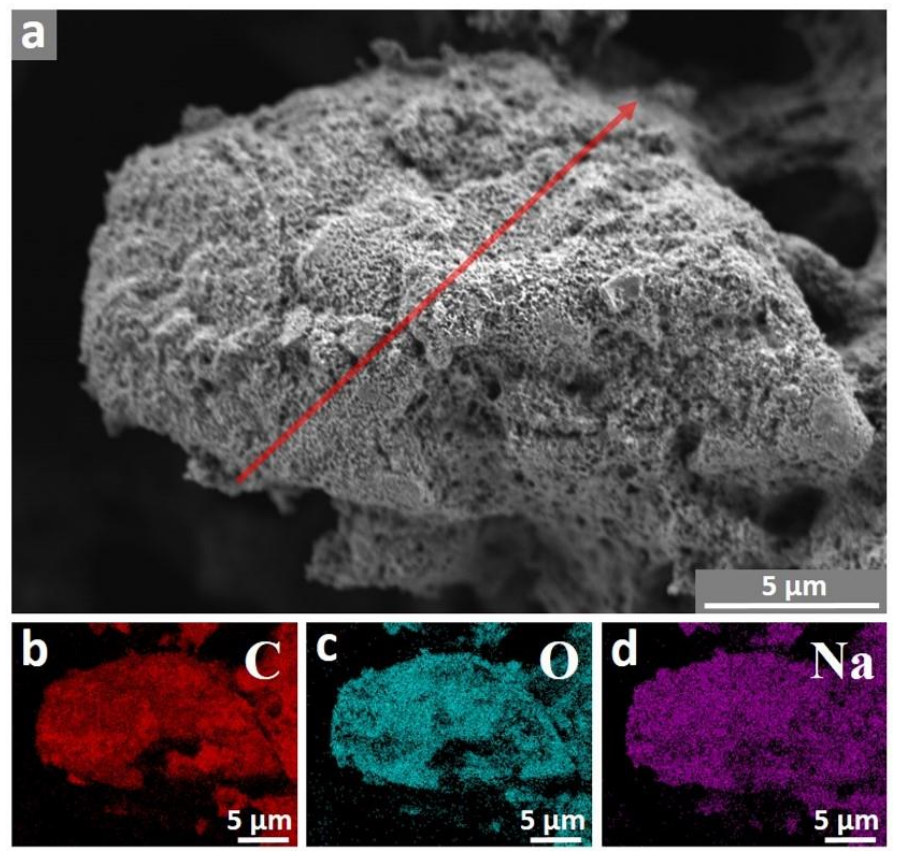

Figure S26. a) SEM image of HOGS at discharged state, with red arrow showing the direction vector of the lameller texture. EDS mappings of $\mathrm{C} \mathrm{b}$ ), $\mathrm{O} c$ ), and, $\mathrm{Na} d$ ) elements. The abundantly and uniformly distributed sodium element on the HOGS particle at discharged state further supports the sodium ions dominated energy storage mechanism of HOGS. 


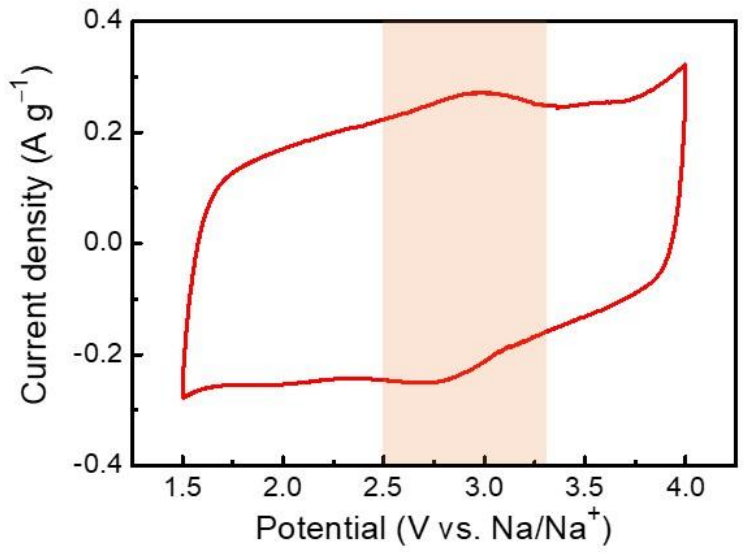

Figure S27. CV curve of HOGS at a low scan rate of $1 \mathrm{mV} \mathrm{s}^{-1}$. The broad redox humps are generated from the sodium ions dominated pseudo-capacitive reaction, and the average redox potential of this reaction is measured to be $2.9 \mathrm{~V} v s . \mathrm{Na} / \mathrm{Na}^{+}$.

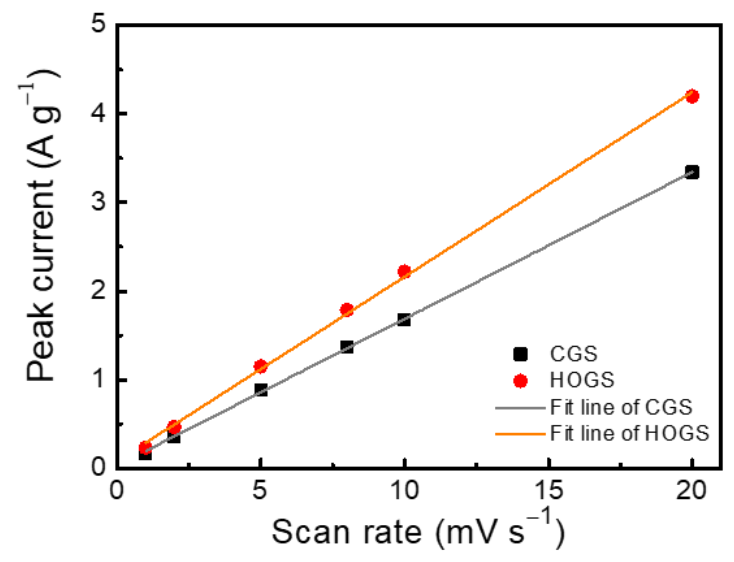

Figure S28. Dependence of peak current upon scan rate for CGS and HOGS. 

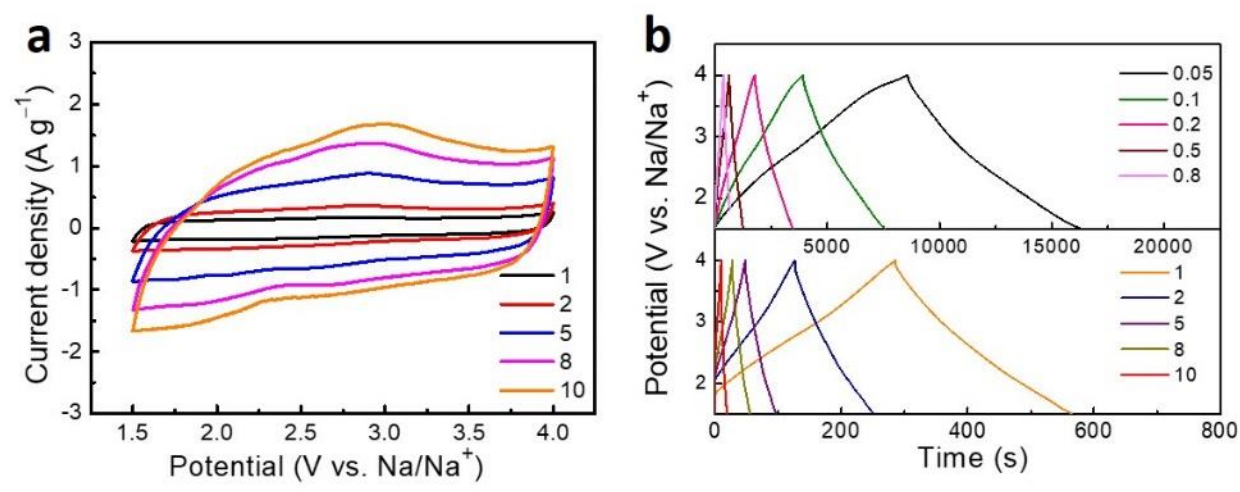

Figure S29. a) CV curves of CGS at different scan rates $\left(\mathrm{mV} \mathrm{s}^{-1}\right)$. b) GCD curves of CGS at different current densities $\left(\mathrm{A} \mathrm{g}^{-1}\right)$.
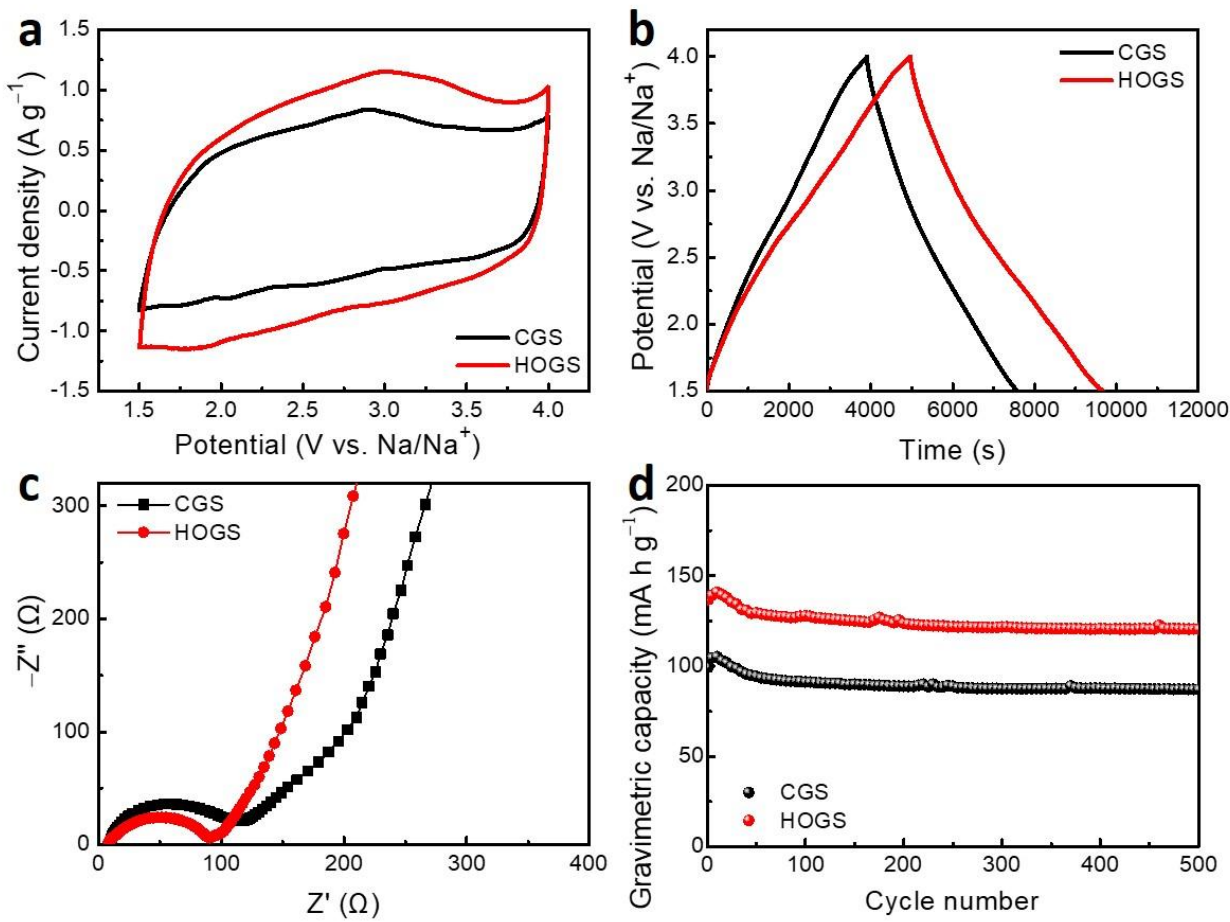

Figure S30. Electrochemical performance comparison of CGS and HOGS. a) CV curves at the scan rate of $5 \mathrm{mV} \mathrm{s}^{-1}$. b) GCD curves at the current density of $0.1 \mathrm{~A} \mathrm{~g}^{-1}$. c) Nyquist plots. d) Cycling performance at the current density of $0.1 \mathrm{~A} \mathrm{~g}^{-1}$. 


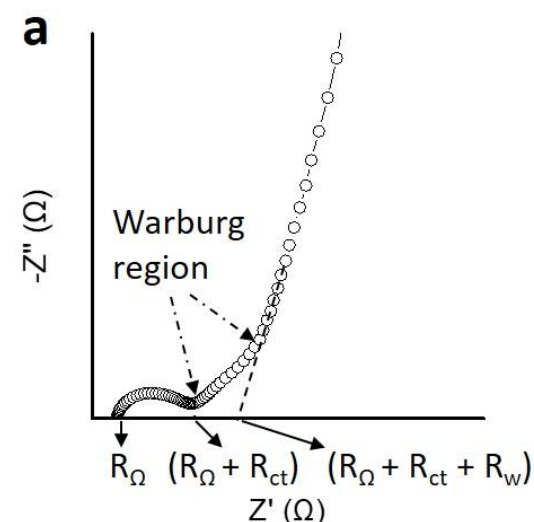

\section{b}

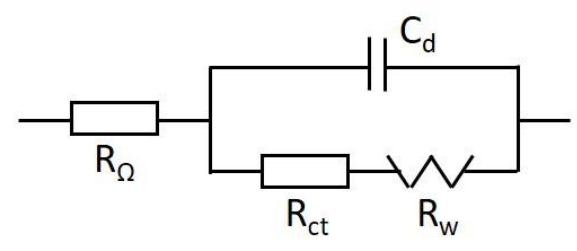

Figure S31. Typical Nyquist plot for porous carbon-based electrode a), and corresponding equivalent circuit $b)$.

For a typical porous carbon-based electrode, its equivalent series resistance ( $\left.\mathrm{R}_{\mathrm{ESR}}\right)$ is mainly composed of three parts; they are intrinsic ohmic resistance $\left(\mathrm{R}_{\Omega}\right)$, interfacial charge transfer resistance $\left(\mathrm{R}_{\mathrm{ct}}\right)$, and Warburg diffusion resistance $\left(\mathrm{R}_{\mathrm{w}}\right)$. Specifically, $\mathrm{R}_{\Omega}$ mainly comes from the intrinsic resistances of electrode material, electrolyte, current collector, leads and separator, as well as the contact resistances between them. $\mathrm{R}_{\mathrm{ct}}$ mainly comes from the electronic and ionic resistances at the interface between the electrode and the electrolyte. $\mathrm{R}_{\mathrm{w}}$ comes from the resistance of ion diffusion from electrolyte into the electrode. Therefore, $\mathrm{R}_{\mathrm{w}}$ is the parameter that is directly related to the ion diffusion, and the ion diffusion coefficient can be calculated by using the following equation:

$$
D=\frac{R^{2} T^{2}}{2 n^{4} F^{4} A^{2} C^{2} \sigma^{2}}
$$

Where $D$ is the ion diffusion coefficient, $R$ is the gas constant, $T$ is the absolute temperature, $n$ is the electron number involved in the redox reaction, $A$ is the geometric area of electrode, $F$ is the Faraday constant, and $C$ is the molar concentration of ions. Additionally, $\sigma$ is the Warburg coefficient, which can be calculated by plotting $Z^{\prime}$ against $\omega^{-1 / 2}$ on the basis of the equation of $Z^{\prime}=R_{\Omega}+R_{c t}+\sigma \omega^{-1 / 2}$ (Figure S 32). As a result, the ion diffusion coefficient of HOGS was calculated to be $8.5 \times 10^{-11} \mathrm{~cm}^{2} \mathrm{~s}^{-1}$, which is much higher than that of CGS $\left(1.3 \times 10^{-11} \mathrm{~cm}^{2} \mathrm{~s}^{-1}\right)$, suggesting the greatly decreased kinetic resistance inside the vertically aligned ordered microstructure of HOGS. 


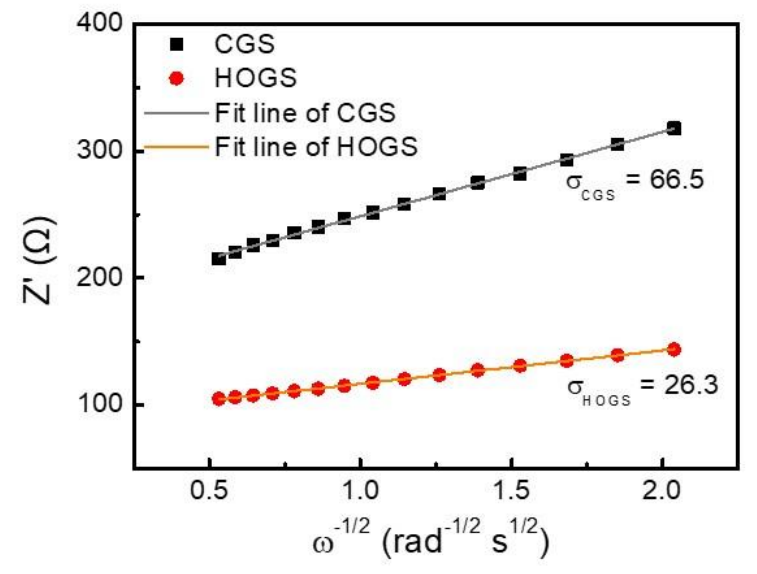

Figure S32. linear plots of Real resistances $\left(Z^{\prime}\right)$ against angular frequencies $\left(\omega^{-1 / 2}\right)$ in the low frequency region.
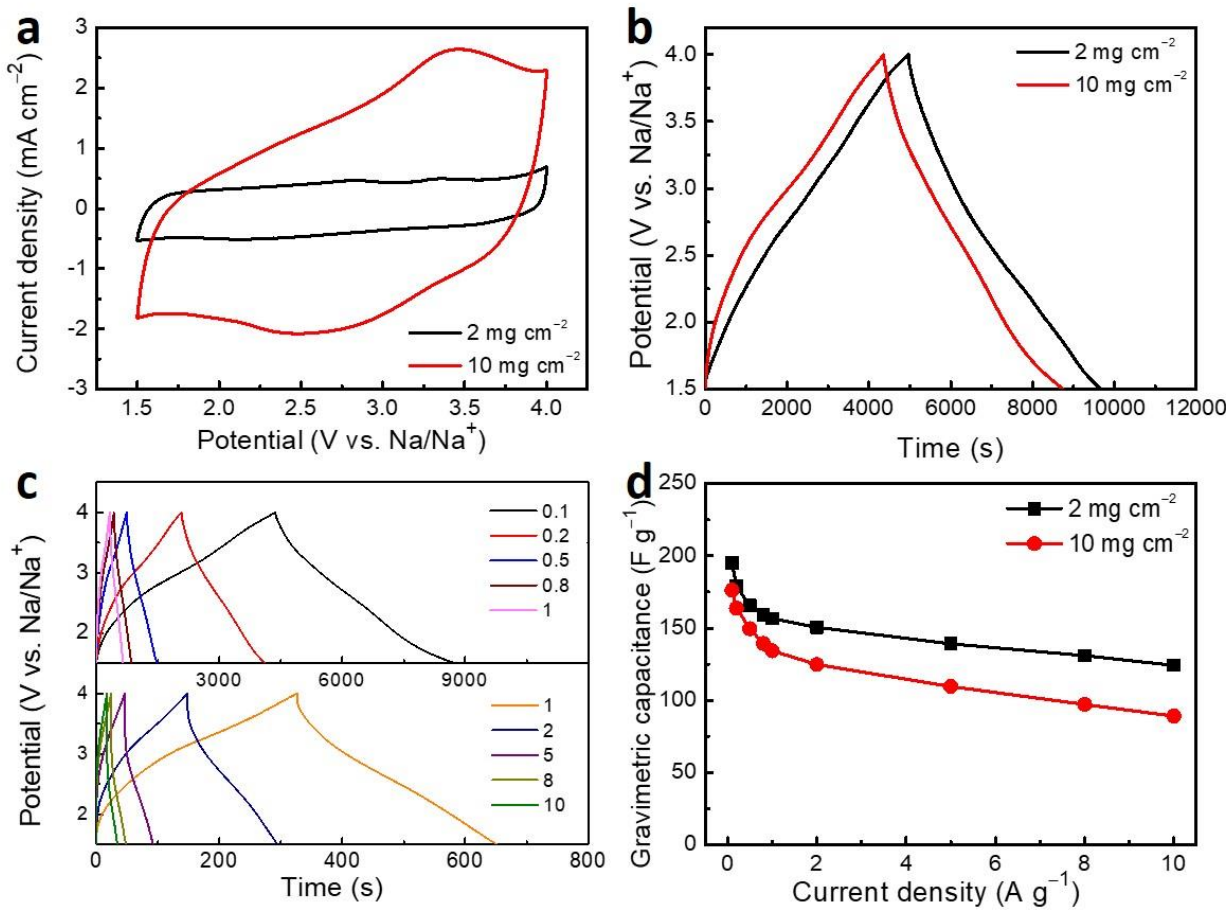

Figure S33. Electrochemical performance of HOGS based cathode with a high areal mass loading of $10 \mathrm{mg} \mathrm{cm}^{-2}$. a) CV curves at the scan rate of $1 \mathrm{mV} \mathrm{s}^{-1}$. b) GCD curves at the current density of $0.1 \mathrm{~A} \mathrm{~g}^{-1}$. c) GCD curves at current densities ranging from 0.1 to $10 \mathrm{~A} \mathrm{~g}^{-1}$. d) Specific capacitances at current densities ranging from 0.1 to $10 \mathrm{~A} \mathrm{~g}^{-1}$. Benefit from the well-constructed electron transfer frameworks and unimpeded ion diffusion channels inside HOGS, only slight performance decline can be identified upon increasing the areal mass loading from 2 to $10 \mathrm{mg} \mathrm{cm}^{-2}$. 


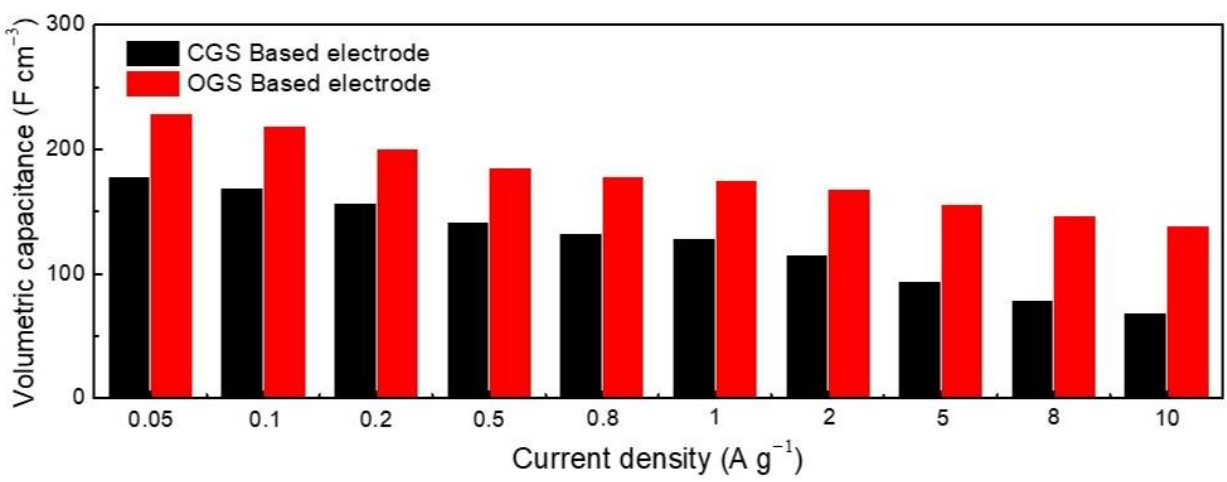

Figure S34. Volumetric capacitances of the CGS and HOGS based electrodes (containing active materials, conductive additives, and binders).

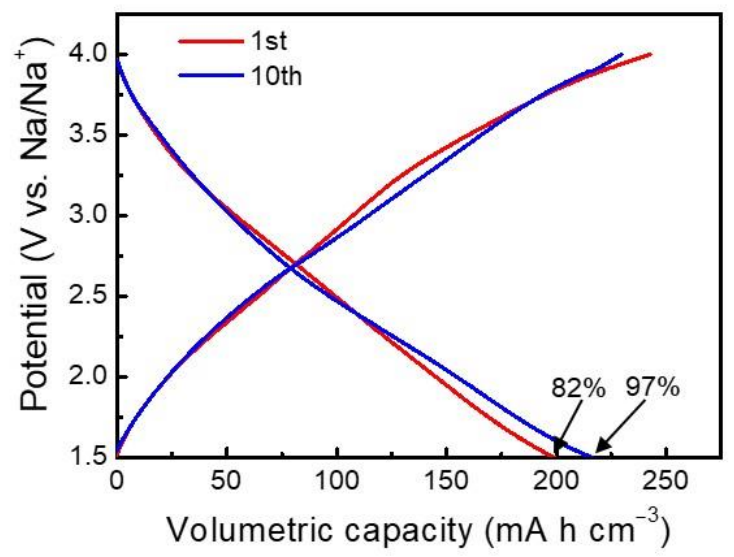

Figure S35. GCG curves of HOGS at the current density of $0.1 \mathrm{~A} \mathrm{~g}^{-1}$. The coulombic efficiency increased rapidly over the initial a few cycles and kept at almost $100 \%$ afterwards, further highlighting the highly efficient capacitive energy storage process of HOGS based cathode. To calculate the coulombic efficiency in first cycle, the halfcell device was firstly discharged to $1.5 \mathrm{~V}$ vs. $\mathrm{Na} / \mathrm{Na}^{+}$from open circuit potential (Figure S24), and then charged/discharged between the normal voltage window between $1.5 \sim 4 \mathrm{~V}$ vs. $\mathrm{Na} / \mathrm{Na}^{+}$. 

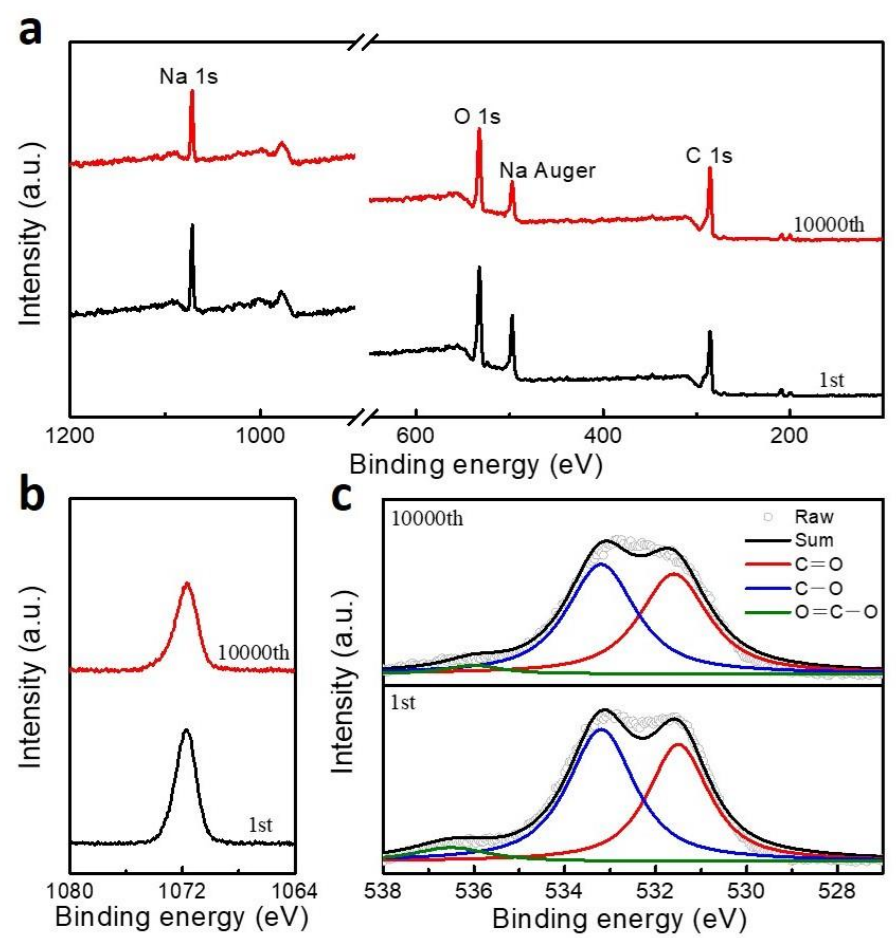

Figure S36. XPS surveys a), Na 1s core level spectra b), and O 1s core level spectra c) of the discharged HOGS electrode after 1st and 10000th cycles. The oxygen atomic content of the long-term cycled electrode is $\sim 3 \%$ lower than that of initial one, demonstrating the slow capacity fading is mainly attributed to the gradual degradation of the surface oxygen functional groups.
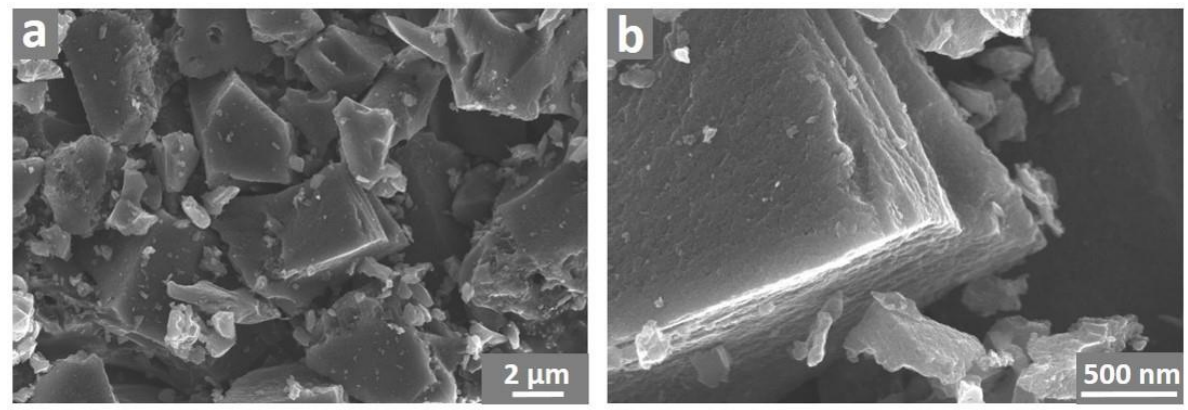

Figure S37. SEM images of HOGS powders. The original ordered microstructure of HOGS was well preserved, demonstrating the structuring stability of HOGS upon grinding and thus guaranteeing the excellent rate capability of HOGS based electrode. 
Table S1. Comparison of CGS and HOGS.

\begin{tabular}{llllll}
\hline & $\begin{array}{l}\text { Packing Density } \\
\left(\mathrm{g} \mathrm{cm}^{-3}\right)\end{array}$ & $\mathrm{SSA}\left(\mathrm{m}^{2} \mathrm{~g}^{-1}\right)$ & $\begin{array}{l}\text { Conductivity } \\
\left(\mathrm{S} \mathrm{m}^{-1}\right)\end{array}$ & $\begin{array}{l}\text { Oxygen atomic } \\
\text { content }(\text { at.\% })\end{array}$ & $I_{\mathrm{D}} / I_{\mathrm{G}}$ \\
\hline \multirow{2}{*}{ CGS } & 1.55 & 268 & 86 & 15.0 & 1.065 \\
HOGS & 1.48 & 529 & 75 & 18.8 & 1.007 \\
\hline
\end{tabular}


Table S2. Comparison of cycle stability and energy/power densities of HOGS based SIC with those of state-of-the-art EES devices.

\begin{tabular}{|c|c|c|c|c|c|}
\hline Type & Voltage & Capacity retention & Energy density & Power density & Ref. \\
\hline \multirow[t]{4}{*}{ SIC } & $1.5-4 \mathrm{~V}$ & $80.6 \%$ after 10000 & $416 \mathrm{Wh} \mathrm{L}^{-1}$ & $148 \mathrm{~W} \mathrm{~L}^{-1}$ & This work \\
\hline & & & $253 \mathrm{Wh} \mathrm{L}^{-1}$ & $36200 \mathrm{~W} \mathrm{~L}^{-1}$ & \\
\hline & & & $282 \mathrm{~W} \mathrm{~h} \mathrm{~kg} \mathrm{~kg}^{-1}$ & $100 \mathrm{~W} \mathrm{~kg}^{-1}$ & \\
\hline & & & $170 \mathrm{~W} \mathrm{~h} \mathrm{~kg}$ & $24500 \mathrm{~W} \mathrm{~kg}^{-1}$ & \\
\hline \multirow[t]{2}{*}{ SIC } & $1.5-4.2 \mathrm{~V}$ & $66 \%$ after 10000 & $201 \mathrm{~W} \mathrm{~h} \mathrm{~kg}{ }^{-1}$ & $285 \mathrm{~W} \mathrm{~kg}^{-1}$ & S1 \\
\hline & & & $50 \mathrm{~W} \mathrm{~h} \mathrm{~kg}^{-1}$ & $16500 \mathrm{~W} \mathrm{~kg}^{-1}$ & \\
\hline \multirow[t]{2}{*}{ SIC } & $0-4.2 \mathrm{~V}$ & $84 \%$ after 1200 & $168 \mathrm{~W} \mathrm{~h} \mathrm{~kg}^{-1}$ & $500 \mathrm{~W} \mathrm{~kg}^{-1}$ & S2 \\
\hline & & & $50 \mathrm{Wh} \mathrm{kg}^{-1}$ & $2800 \mathrm{~W} \mathrm{~kg}^{-1}$ & \\
\hline \multirow[t]{2}{*}{ SIC } & $0-4.4 \mathrm{~V}$ & $70 \%$ after 1000 & $157 \mathrm{~W} \mathrm{~h} \mathrm{~kg}^{-1}$ & $620 \mathrm{~W} \mathrm{~kg}^{-1}$ & $\mathrm{~S} 3$ \\
\hline & & & $25 \mathrm{~W} \mathrm{~h} \mathrm{~kg}^{-1}$ & $2000 \mathrm{~W} \mathrm{~kg}^{-1}$ & \\
\hline \multirow[t]{2}{*}{ SIC } & $0-4 \mathrm{~V}$ & $80 \%$ after 3000 & $122 \mathrm{~W} \mathrm{~h} \mathrm{~kg}^{-1}$ & $67 \mathrm{~W} \mathrm{~kg}^{-1}$ & $\mathrm{~S} 4$ \\
\hline & & & $45 \mathrm{~W} \mathrm{~h} \mathrm{~kg}^{-1}$ & $12000 \mathrm{~W} \mathrm{~kg}^{-1}$ & \\
\hline \multirow[t]{2}{*}{ SIC } & $0-4 \mathrm{~V}$ & $83 \%$ after 5000 & $111 \mathrm{~W} \mathrm{~h} \mathrm{~kg}^{-1}$ & $67 \mathrm{~W} \mathrm{~kg}^{-1}$ & S5 \\
\hline & & & $38 \mathrm{~W} \mathrm{~h} \mathrm{~kg}^{-1}$ & $14550 \mathrm{~W} \mathrm{~kg}^{-1}$ & \\
\hline \multirow[t]{2}{*}{ SIC } & $1-3.8 \mathrm{~V}$ & $77.3 \%$ after 10000 & $114 \mathrm{~W} \mathrm{~h} \mathrm{~kg}^{-1}$ & $240 \mathrm{~W} \mathrm{~kg}^{-1}$ & S6 \\
\hline & & & $19 \mathrm{~W} \mathrm{~h} \mathrm{~kg}^{-1}$ & $12000 \mathrm{~W} \mathrm{~kg}^{-1}$ & \\
\hline \multirow[t]{2}{*}{ LIC } & $0-4 \mathrm{~V}$ & $91 \%$ after 4000 & $262 \mathrm{~W} \mathrm{~h} \mathrm{~kg}^{-1}$ & $450 \mathrm{~W} \mathrm{~kg}^{-1}$ & S7 \\
\hline & & & $78 \mathrm{~W} \mathrm{~h} \mathrm{~kg}^{-1}$ & $9000 \mathrm{~W} \mathrm{~kg}^{-1}$ & \\
\hline \multirow[t]{2}{*}{ LIC } & $0-4.5 \mathrm{~V}$ & $81 \%$ after 5000 & $220 \mathrm{~W} \mathrm{~h} \mathrm{~kg}{ }^{-1}$ & $225 \mathrm{~W} \mathrm{~kg}^{-1}$ & S8 \\
\hline & & & $104 \mathrm{~W} \mathrm{~h} \mathrm{~kg}^{-1}$ & $22500 \mathrm{~W} \mathrm{~kg}^{-1}$ & \\
\hline \multirow[t]{2}{*}{ LIC } & $1.5-5 \mathrm{~V}$ & $65 \%$ after 10000 & $146 \mathrm{~W} \mathrm{~h} \mathrm{~kg}^{-1}$ & $65 \mathrm{~W} \mathrm{~kg}^{-1}$ & S9 \\
\hline & & & $18 \mathrm{~W} \mathrm{~h} \mathrm{~kg}^{-1}$ & $18000 \mathrm{~W} \mathrm{~kg}^{-1}$ & \\
\hline \multirow[t]{2}{*}{ LIC } & $2-4 \mathrm{~V}$ & $97 \%$ after 600 & $82 \mathrm{~W} \mathrm{~h} \mathrm{~kg}^{-1}$ & $100 \mathrm{~W} \mathrm{~kg}^{-1}$ & S10 \\
\hline & & & $14 \mathrm{~W} \mathrm{~h} \mathrm{~kg}^{-1}$ & $20000 \mathrm{~W} \mathrm{~kg}^{-1}$ & \\
\hline \multirow[t]{2}{*}{ LIC } & $2-4 \mathrm{~V}$ & $97 \%$ after 3500 & $135 \mathrm{~W} \mathrm{~h} \mathrm{~kg}^{-1}$ & $50 \mathrm{~W} \mathrm{~kg}^{-1}$ & S11 \\
\hline & & & $105 \mathrm{~W} \mathrm{~h} \mathrm{~kg}^{-1}$ & $1500 \mathrm{~W} \mathrm{~kg}^{-1}$ & \\
\hline \multirow[t]{2}{*}{ LIC } & $0-4.4 \mathrm{~V}$ & $63 \%$ after 15000 & $115 \mathrm{~W} \mathrm{~h} \mathrm{~kg}^{-1}$ & $25 \mathrm{~W} \mathrm{~kg}^{-1}$ & S12 \\
\hline & & & $16 \mathrm{~W} \mathrm{~h} \mathrm{~kg}^{-1}$ & $15000 \mathrm{~W} \mathrm{~kg}^{-1}$ & \\
\hline \multirow[t]{2}{*}{ LIC } & $1-4 \mathrm{~V}$ & $83 \%$ after 5000 & $184 \mathrm{~W} \mathrm{~h} \mathrm{~kg}^{-1}$ & $83 \mathrm{~W} \mathrm{~kg}^{-1}$ & S13 \\
\hline & & & $83 \mathrm{~W} \mathrm{~h} \mathrm{~kg}^{-1}$ & $18000 \mathrm{~W} \mathrm{~kg}^{-1}$ & \\
\hline \multirow[t]{2}{*}{ LIC } & $1-4 \mathrm{~V}$ & $70 \%$ after 1000 & $204 \mathrm{~W} \mathrm{~h} \mathrm{~kg}^{-1}$ & $55 \mathrm{~W} \mathrm{~kg}^{-1}$ & S14 \\
\hline & & & $85 \mathrm{~W} \mathrm{~h} \mathrm{~kg}^{-1}$ & $2650 \mathrm{~W} \mathrm{~kg}^{-1}$ & \\
\hline SIB & $1.5-3.8 \mathrm{~V}$ & $80 \%$ after 300 & $240 \mathrm{~W} \mathrm{~h} \mathrm{~kg}^{-1}$ & - & S15 \\
\hline SIB & $2-4 \mathrm{~V}$ & $75 \%$ after 100 & $126 \mathrm{~W} \mathrm{~h} \mathrm{~kg}^{-1}$ & - & S16 \\
\hline SIB & $1.7-3.8 \mathrm{~V}$ & $54 \%$ after 250 & $130 \mathrm{~W} \mathrm{~h} \mathrm{~kg}{ }^{-1}$ & - & S17 \\
\hline
\end{tabular}


Table S3. Comparison of energy/power densities and cycle stability of HOGS with those of state-of-the-art cathode materials for SICs.

\begin{tabular}{|c|c|c|c|c|}
\hline Materials & Energy density & Power density & Capacity retention & Ref. \\
\hline \multirow[t]{4}{*}{ HOGS } & $832 \mathrm{Wh} \mathrm{L} \mathrm{L}^{-1}$ & $296 \mathrm{~W} \mathrm{~L}^{-1}$ & $80.6 \%$ after 10000 & This \\
\hline & $506 \mathrm{~W} h \mathrm{~L}^{-1}$ & $72400 \mathrm{~W} \mathrm{~L} \mathrm{~L}^{-1}$ & & work \\
\hline & $564 \mathrm{~W} \mathrm{~h} \mathrm{~kg}^{-1}$ & $200 \mathrm{~W} \mathrm{~kg}^{-1}$ & & \\
\hline & $340 \mathrm{~W} \mathrm{~h} \mathrm{kg-1}$ & $49000 \mathrm{~W} \mathrm{~kg}-1$ & & \\
\hline $\mathrm{P}-\mathrm{aCN}$ & $147 \mathrm{~W} \mathrm{~h} \mathrm{~kg}^{-1}$ & $500 \mathrm{~W} \mathrm{~kg}^{-1}$ & $96 \%$ after 100000 & $\mathrm{~S} 18$ \\
\hline $\mathrm{AC}$ & $111 \mathrm{~W} \mathrm{~h} \mathrm{~kg}^{-1}$ & $800 \mathrm{~W} \mathrm{~kg}^{-1}$ & $86 \%$ after 3000 & S19 \\
\hline Carbon microsphere & $54 \mathrm{~W} \mathrm{~h} \mathrm{~kg}^{-1}$ & $800 \mathrm{~W} \mathrm{~kg}^{-1}$ & $92 \%$ after 1000 & S20 \\
\hline Graphene & $39 \mathrm{~W} \mathrm{~h} \mathrm{~kg}^{-1}$ & $333 \mathrm{~W} \mathrm{~kg}^{-1}$ & $91 \%$ after 2000 & $\mathrm{~S} 21$ \\
\hline 3D graphdiyne & $182 \mathrm{~W} \mathrm{~h} \mathrm{~kg}^{-1}$ & $300 \mathrm{~W} \mathrm{~kg}^{-1}$ & $90 \%$ after 3000 & S22 \\
\hline 3D graphene & $111 \mathrm{~W} \mathrm{~h} \mathrm{~kg}^{-1}$ & $200 \mathrm{~W} \mathrm{~kg}^{-1}$ & $95 \%$ after 1000 & $\mathrm{~S} 23$ \\
\hline $\mathrm{SnS}_{2} /$ graphene & $17 \mathrm{~W} \mathrm{~h} \mathrm{~kg}^{-1}$ & $488 \mathrm{~W} \mathrm{~kg}^{-1}$ & $95 \%$ after 1000 & S24 \\
\hline $\mathrm{TiO}_{2} /$ graphene & $64 \mathrm{~W} \mathrm{~h} \mathrm{~kg}^{-1}$ & $56 \mathrm{~W} \mathrm{~kg}^{-1}$ & $90 \%$ after 10000 & S25 \\
\hline $\mathrm{Nb}_{2} \mathrm{O}_{5} /$ graphene & $113 \mathrm{~W} \mathrm{~h} \mathrm{~kg}^{-1}$ & $80 \mathrm{~W} \mathrm{~kg}^{-1}$ & $97 \%$ after 1500 & S26 \\
\hline $\mathrm{NaTi}_{2}\left(\mathrm{PO}_{4}\right)_{3} /$ graphene & $86 \mathrm{~W} \mathrm{~h} \mathrm{~kg}^{-1}$ & $400 \mathrm{~W} \mathrm{~kg}^{-1}$ & $90 \%$ after 75000 & S27 \\
\hline $\mathrm{Na}_{2} \mathrm{Ti}_{3} \mathrm{O}_{7} / \mathrm{ACF}$ & $128 \mathrm{~W} \mathrm{~h} \mathrm{~kg}^{-1}$ & $96 \mathrm{~W} \mathrm{~kg}^{-1}$ & $85 \%$ after 1000 & $\mathrm{~S} 28$ \\
\hline
\end{tabular}

Note: All the energy/power densities listed here are based on the electrode materials, rather than the whole SIC devices. 


\section{References}

S1. Li, B.; Dai, F.; Xiao, Q.; Yang, L.; Shen, J.; Zhang, C.; Cai, M. Nitrogen-Doped Activated Carbon for a High Energy Hybrid Supercapacitor. Energy Environ. Sci. 2016, 9, 102-106.

S2. Wang, F.; Wang, X.; Chang, Z.; Wu, X.; Liu, X.; Fu, L.; Zhu, Y.; Wu, Y.; Huang, W. A Quasi-Solid-State Sodium-Ion Capacitor with High Energy Density. Adv. Mater. 2015, 27, 6962-6968.

S3. Wang, C.; Wang, F.; Liu, Z.; Zhao, Y.; Liu, Y.; Yue, Q.; Zhu, H.; Deng, Y.; Wu, Y.; Zhao, D. N-Doped Carbon Hollow Microspheres for Metal-Free Quasi-Solid-State Full Sodium-Ion Capacitors. Nano Energy 2017, 41, 674-680.

S4. Wang, H.; Mitlin, D.; Ding, J.; Li, Z.; Cui, K. Excellent Energy-Power Characteristics from a Hybrid Sodium Ion Capacitor Based on Identical Carbon Nanosheets in Both Electrodes. J. Mater. Chem. A 2016, 4, 5149-5158.

S5. Ding, J.; Li, Z.; Cui, K.; Boyer, S.; Karpuzov, D.; Mitlin, D. Heteroatom Enhanced Sodium Ion Capacity and Rate Capability in a Hydrogel Derived Carbon Give Record Performance in a Hybrid Ion Capacitor. Nano Energy 2016, 23, 129-137.

S6. Wang, R.; Wang, S.; Peng, X.; Zhang, Y.; Jin, D.; Chu, P. K.; Zhang, L. Elucidating the Intercalation Pseudocapacitance Mechanism of $\mathrm{MoS}_{2}$-Carbon Monolayer Interoverlapped Superstructure: Toward High-Performance Sodium-Ion-Based Hybrid Supercapacitor. ACS Appl. Mater. Interfaces 2017, 9, 32745-32755.

S7. Dubal, D. P.; Gomez-Romero, P. All Nanocarbon Li-Ion Capacitor with High Energy and High Power Density. Mater. Today Energy 2018, 8, 109-117.

S8. Xia, Q.; Yang, H.; Wang, M.; Yang, M.; Guo, Q.; Wan, L.; Xia, H.; Yu, Y. High Energy and High Power Lithium-Ion Capacitors Based on Boron and Nitrogen Dual-Doped 3D Carbon Nanofibers as Both Cathode and Anode. Adv. Energy Mater. 2017, 7, 1701336.

S9. Khomenko, V.; Raymundo-Pinero, E.; Beguin, F. High-Energy Density Graphite/AC Capacitor in Organic Electrolyte. J. Power Sources 2008, 177, 643651.

S10. Cao, W. J.; Zheng, J. P. Li-Ion Capacitors with Carbon Cathode and Hard Carbon/Stabilized Lithium Metal Powder Anode Electrodes. J. Power Sources 2012, 213, 180-185.

S11. Ji Hoon, L.; Weon Ho, S.; Soo Yeon, L.; Byung Gon, K.; Jang Wook, C. Modified Graphite and Graphene Electrodes for High-Performance Lithium Ion Hybrid Capacitors. Mater. Renew. Sustain. Energy 2014, 3, 22. 
S12. Schroeder, M.; Winter, M.; Passerini, S.; Balducci, A. On the Cycling Stability of Lithium-Ion Capacitors Containing Soft Carbon as Anodic Material. J. Power Sources 2013, 238, 388-394.

S13. Wang, H.; Xu, Z.; Li, Z.; Cui, K.; Ding, J.; Kohandehghan, A.; Tan, X.; Zahiri, B.; Olsen, B. C.; Holt, C. M. B.; Mitlin, D. Hybrid Device Employing ThreeDimensional Arrays of $\mathrm{MnO}$ in Carbon Nanosheets Bridges BatterySupercapacitor Divide. Nano Lett. 2014, 14, 1987-1994.

S14. Zhang, F.; Zhang, T.; Yang, X.; Zhang, L.; Leng, K.; Huang, Y.; Chen, Y. A HighPerformance Supercapacitor-Battery Hybrid Energy Storage Device Based on Graphene-Enhanced Electrode Materials with Ultrahigh Energy Density. Energy Environ. Sci. 2013, 6, 1623-1632.

S15. Hwang, J.-Y.; Oh, S.-M.; Myung, S.-T.; Chung, K. Y.; Belharouak, I.; Sun, Y.-K. Radially Aligned Hierarchical Columnar Structure as a Cathode Material for High Energy Density Sodium-Ion Batteries. Nat. Commun. 2015, 6, 6865.

S16. Ni, J.; Fu, S.; Wu, C.; Zhao, Y.; Maier, J.; Yu, Y.; Li, L. Superior Sodium Storage in $\mathrm{Na}_{2} \mathrm{Ti}_{3} \mathrm{O}_{7}$ Nanotube Arrays through Surface Engineering. Adv. Energy Mater. 2016, 6, 1502568.

S17. Li, H.; Peng, L.; Zhu, Y.; Chen, D.; Zhang, X.; Yu, G. An Advanced High-Energy Sodium Ion Full Battery Based on Nanostructured $\mathrm{Na}_{2} \mathrm{Ti}_{3} \mathrm{O}_{7} / \mathrm{VO}_{\mathrm{P}} \mathrm{O}_{4}$ Layered Materials. Energy Environ. Sci. 2016, 9, 3399-3405.

S18. Park, S. K.; Kwon, S. H.; Lee, S. G.; Choi, M. S.; Suh, D. H.; Nakhanivej, P.; Lee, H.; Park, H. S. $10^{5}$ Cyclable Pseudocapacitive Na-Ion Storage of Hierarchically Structured Phosphorus-Incorporating Nanoporous Carbons in Organic Electrolytes. ACS Energy Lett. 2018, 3, 724-732.

S19. Li, H.; Peng, L.; Zhu, Y.; Zhang, X.; Yu, G. Achieving High-Energy-High-Power Density in a Flexible Quasi-Solid-State Sodium Ion Capacitor. Nano Lett. 2016, $16,5938-5943$.

S20.Lu, K.; Song, B.; Gao, X.; Dai, H.; Zhang, J.; Ma, H. High-Energy Cobalt Hexacyanoferrate and Carbon Micro-Spheres Aqueous Sodium-Ion Capacitors. $J$. Power Sources 2016, 303, 347-353.

S21. Krishnamoorthy, K.; Pazhamalai, P.; Sahoo, S.; Lim, J. H.; Choi, K. H.; Kim, S. J. A High-Energy Aqueous Sodium-Ion Capacitor with Nickel Hexacyanoferrate and Graphene Electrodes. ChemElectroChem 2017, 4, 3302-3308.

S22. Wang, K.; Wang, N.; He, J.; Yang, Z.; Shen, X.; Huang, C. Preparation of 3D Architecture Graphdiyne Nanosheets for High-Performance Sodium-Ion Batteries 
and Capacitors. ACS Appl. Mater. Interfaces 2017, 9, 40604-40613.

S23. Yang, B.; Chen, J.; Lei, S.; Guo, R.; Li, H.; Shi, S.; Yan, X. Spontaneous Growth of 3D Framework Carbon from Sodium Citrate for High Energy- and PowerDensity and Long-Life Sodium-Ion Hybrid Capacitors. Adv. Energy Mater. 2018, 8, 1702409 .

S24. Chauhan, H.; Singh, M. K.; Kumar, P.; Hashmi, S. A.; Deka, S. Development of $\mathrm{SnS}_{2} / \mathrm{RGO}$ Nanosheet Composite for Cost-Effective Aqueous Hybrid Supercapacitors. Nanotechnology 2017, 28, 025401.

S25. Le, Z.; Liu, F.; Nie, P.; Li, X.; Liu, X.; Bian, Z.; Chen, G.; Wu, H. B.; Lu, Y. Pseudocapacitive Sodium Storage in Mesoporous Single-Crystal-like $\mathrm{TiO}_{2}$ Graphene Nanocomposite Enables High-Performance Sodium-Ion Capacitors. ACS Nano 2017, 11, 2952-2960.

S26. Wang, X.; Li, Q.; Zhang, L.; Hu, Z.; Yu, L.; Jiang, T.; Lu, C.; Yan, C.; Sun, J.; Liu, Z. Caging $\mathrm{Nb}_{2} \mathrm{O}_{5}$ Nanowires in PECVD-Derived Graphene Capsules toward Bendable Sodium-Ion Hybrid Supercapacitors. Adv. Mater. 2018, 30, 1800963.

S27. Thangavel, R.; Moorthy, B.; Kim, D. K.; Lee, Y.-S. Pushing the Energy Output and Cyclability of Sodium Hybrid Capacitors at High Power to New Limits. Adv. Energy Mater. 2017, 7, 1602654.

S28. Qiu, X.; Zhang, X.; Fan, L.-Z. In Situ Synthesis of a Highly Active $\mathrm{Na}_{2} \mathrm{Ti}_{3} \mathrm{O}_{7}$ Nanosheet on an Activated Carbon Fiber as an Anode for High-Energy Density Supercapacitors. J. Mater. Chem. A 2018, 6, 16186-16195. 